\title{
A QUESTÃO DA UNIVERSALIDADE DAS CATEGORIAS JURÍDICAS OCIDENTAIS A PARTIR DA ABORDAGEM ANTROPOLÓGICA: NOTA SOBRE A DISCUSSÃO ENTRE MAX GLUCKMAN E PAUL BOHANNAN
}

\author{
THE QUESTION OF UNIVERSALITY OF WESTERN LEGAL CATEGORIES FROM THE \\ ANTHROPOLOGICAL POINT OF VIEW: NOTE ON THE DISCUSSION BETWEEN MAX GLUCKMAN \\ AND PAUL BOHANNAN
}

Orlando Villas Bôas Filho*

\begin{abstract}
Resumo:
Este artigo pretende examinar a controvérsia entre Max Gluckman e Paul Bohannan, especialmente no que tange à questão de como proceder a uma análise comparativa da regulação jurídica de culturas homeomorfas. Para tanto, reconstrói alguns aspectos fundamentais que caracterizaram as perspectivas de Bohannan e de Gluckman. Por fim, para sublinhar a relevância da controvérsia entre esses dois autores, recupera alguns de seus reflexos na discussão antropológica acerca do direito.
\end{abstract}

Palavras-chave: Antropologia jurídica. Etnografia jurídica. Comparação antropológica. Etnocentrismo. Epistemologia.

\begin{abstract}
:
This paper analyzes the controversy between Max Gluckman and Paul Bohannan, especially regarding the question of how making a comparative analysis of legal regulation of homeomorphic cultures. Therefore, it reconstructs some fundamental aspects that characterized the viewpoints of Bohannan and Gluckman. Finally, to underline the relevance of controversy between these two authors, the author recovers some of its reflections on the anthropological discussion of law.
\end{abstract}

Keywords: Legal Anthropology. Legal Ethnography. Anthropological comparison. Ethnocentrism. Epistemology.

Introdução

Pode-se afirmar que uma das contribuições mais importantes que a abordagem antropológica pode fornecer à compreensão do "fenômeno jurídico" consiste no descentramento crítico relativamente às categorias que norteiam nossa percepção e que, não poucas vezes, impedem a apreensão adequada da multiplicidade de formas de expressão que tal fenômeno experimenta. Conforme ressalta Robert Vachon, existem não apenas diversas variantes, modalidades e modos de aplicação daquilo que o Ocidente ${ }^{1}$

\footnotetext{
Professor Doutor da Faculdade de Direito da Universidade de São Paulo e da Faculdade de Direito da Universidade Presbiteriana Mackenzie.

1 Como observa Edward Said, "Ocidente" e "Oriente" não têm "estabilidade ontológica", ou seja, não são 
denomina de direito, mas sim diversas "culturas jurídicas" cujas diferenças não são simplesmente procedimentais, situando-se, ao contrário, num plano substancial. Tratase, nesse sentido, de "culturas jurídicas homeomorfas", ou seja, marcadas por diferenças substanciais no que concerne à sua natureza e aos seus postulados. ${ }^{2}$ Diante desse cenário, colocam-se, por exemplo, as seguintes questões: como analisar a regulação jurídica diante da diversidade de culturas jurídicas? Como proceder a uma comparação de culturas substancialmente distintas sem que isso implique a projeção de categorias de umas sobre as outras? Como evitar a descaracterização das formas de regulação que, em outras culturas, são qualificáveis como jurídicas ao traduzi-las nos termos das ciências sociais ocidentais? Qual a linguagem adequada para realizar a descrição das regulações jurídicas existentes em outras culturas? Como conciliar a comparação com uma etnografia atenta às especificidades de formações culturais díspares?

É em meio a esse horizonte que se coloca a discussão relativa à universalidade das categorias jurídicas ocidentais para a descrição, compreensão e análise das formas de expressão assumidas pela regulação jurídica em outras culturas, a qual encontra uma expressiva ilustração na controvérsia ocorrida entre Paul Bohannan e Max Gluckman. ${ }^{3}$ Conforme Shelton H. Davis, trata-se de uma controvérsia da mais alta importância epistemológica, na medida em que dela derivam não apenas relevantes questões de método, mas, inclusive, problematizações fundamentais acerca do próprio conhecimento antropológico. ${ }^{4}$ Referindo-se a essa controvérsia, Sally Falk Moore enfatiza que ela remete a questões centrais da discussão antropológica, tais como a própria definição do que pode ser considerado uma unidade válida para a comparação ou o que, em última instância, pode ser reputado como objeto de estudo. ${ }^{5}$

"fatos inertes da natureza", e sim construtos imaginários que, apesar de não serem desprovidos de uma realidade correspondente, não a esgotam ou representam cabalmente, pois a complexidade da realidade não é, evidentemente, redutível a essas figurações imaginárias que, ademais, são atravessadas por relações de poder. Cf. SAID, Edward W. Orientalismo: o Oriente como invenção do Ocidente. Tradução de Rosana Eichenberg. São Paulo: Companhia das Letras, 2007. p. 13 e 31. Referindo-se ao projeto de Said, Marshall Sahlins afirma que "in anthropology there are some things that are better left un-Said" (SAHLINS, Marshall David. Esperando Foucault, ainda. Tradução de Marcela Coelho de Souza e Eduardo Viveiros de Castro. São Paulo: Cosac Naify, 2013. p. 53).

2 Cf. VACHON, Robert. L'Etude du pluralisme juridique: une approche diatopique et dialogale. The Journal of Legal Pluralism and Unofficial Law, London, v. 22, n. 29, January 1990. p. 164-165.

3 Cf. ROULAND, Norbert. Anthropologie juridique. Paris: Presses Universitaires de France, 1988. p. 173.

4 Cf. DAVIS, Shelton H. Introdução. In:__ (Org.). Antropologia do direito: estudo comparativo de categorias de dívida e contrato. Tradução de Vera Maria Cândido Pereira. Rio de Janeiro: Zahar, 1973. p. 24. Sally Falk Moore aponta uma série de questões epistemológicas complexas que derivam desse debate (cf. MOORE, Sally Falk. Law as process. An anthropological approach. Hamburg: LIT, 2000. p. 148).

5 Referindo-se à discussão entre Max Gluckman e Paul Bohannan, especialmente tal como ela se expressou na Wenner-Gren Conference de 1966, Sally Falk Moore enfatiza que "the discussion of concepts and comparisons that follows is not simply a discussion of techniques. Bohannan's and Gluckman's papers ask, 'What is a valid unit of comparison?' but, in a deeper sense, the answer show differences in point 
Além disso, não se pode desconsiderar que a controvérsia entre Max Gluckman e Paul Bohannan também conduz a situações dilemáticas, senão aporéticas, relativamente ao saber antropológico. A respeito, Roberto Kant de Lima aponta os “dilemas insolúveis", ínsitos ao saber antropológico, que se explicitariam claramente nas posições antagônicas sustentadas por Gluckman e Bohannan. Segundo ele, da discussão que os opôs decorreria, por exemplo, a questão relativa a como evitar a esterilidade de uma comparação que, dada a sua generalidade, simplesmente constata que as sociedades são diversas sem, entretanto, cair num relativismo radical que, em última instância, inviabiliza a comparação. Nas palavras de Kant de Lima, a percepção da diferença, para qual se vocaciona a análise antropológica,

[...] leva freqüentemente este tipo de reflexão a dilemas insolúveis: um deles a constatação teoricamente inútil de que as coisas em uma sociedade "funcionam" de uma determinada maneira, embora diferentemente em cada uma delas, o que apenas nos garante que as sociedades têm estratégias próprias de reprodução. A garantia da especificidade é, no entanto, inibidora da generalização. Descamba-se muita vez em um relativismo radical que implica admitir a impossibilidade do saber antropológico pela inviabilidade da comparação entre heterogeneidades irredutíveis. ${ }^{6}$

A importância das posições que se antagonizam no debate havido entre Max Gluckman e Paul Bohannan serve, inclusive, para ilustrar posturas analíticas díspares desenvolvidas na discussão antropológica. Rodolfo Sacco, por exemplo, alude à divisão existente entre os antropólogos que organizam seu material a partir das categorias que lhes são familiares e os que condenam incisivamente tal procedimento. Como exemplo do primeiro grupo, cita Max Gluckman. Como exemplo do segundo, indica Paul Bohannan. Como exemplo de posturas intermediárias ao posicionamento de ambos, faz referência a Jean Poirier e Sally Falk Moore. ${ }^{7}$ John L. Comaroff e Simon Roberts, ao distinguirem

of view about the question, 'What is the subject of study?"' (MOORE, Sally Falk. Law as process. An anthropological approach. Hamburg: LIT, 2000. p. 139).

6 LIMA, Roberto Kant de. Por uma antropologia do direito, no Brasil. In: Ensaios de antropologia e de direito: acesso à justiça e processos institucionais de administração de conflitos e produção da verdade em uma perspectiva comparada. Rio de Janeiro: Lumen Juris, 2008. p. 9; LIMA, Roberto Kant de; VARELLA, Alex. Saber jurídico e direito à diferença no Brasil: questões de teoria e método em uma perspectiva comparativa. In: LIMA, Roberto Kant de. Ensaios de antropologia e de direito: acesso à justiça e processos institucionais de administração de conflitos e produção da verdade em uma perspectiva comparada. Rio de Janeiro: Lumen Juris, 2008. p. 105.

7 Cf. SACCO, Rodolfo. Antropologia jurídica: contribuição para uma macro-história do direito. Tradução de Carlo Alberto Dastoli. São Paulo: Martins Fontes, 2013. p. 35-36. A respeito, ver também: NADER, Laura. Introduction. In: NADER, Laura (Ed.). Law in culture and society. Berkeley, California: University of California Press, 1997. p. 2-3. 
os paradigmas normativo (rule-centered paradigm) e processual (processual paradigm), que, segundo eles, se oporiam no âmbito da antropologia jurídica, dão especial destaque às reverberações do debate entre Gluckman e Bohannan no âmbito da crítica ao primeiro desses paradigmas. ${ }^{8}$

O que naturalmente se coloca no horizonte da discussão entre Max Gluckman e Paul Bohannan é a problemática do etnocentrismo, já há muito tempo ressaltada pela antropologia, ${ }^{9}$ uma vez que ela, conforme ressalta Tzvetan Todorov, seria, por assim dizer, a caricatura natural do universalismo que projeta de maneira acrítica valores particulares ao patamar de universais. ${ }^{10}$ Trata-se, assim, de uma postura que, conforme ressaltava Claude Lévi-Strauss, é refratária à diversidade cultural, ${ }^{11}$ o que a torna um tema central no âmbito da discussão antropológica. Pierre Clastres sublinhava, inclusive, que o etnocentrismo constituiria um "obstáculo epistemológico" a ser enfrentado. ${ }^{12}$ Aliás, cabe notar que, mesmo no campo sociológico, Pierre Bourdieu, Jean-Claude Chamboderon e Jean-Claude Passeron enfatizam que o etnocentrismo, concebido como o "pressuposto da ausência de pressupostos", seria importante obstáculo, prenhe de consequências epistemológicas que,

8 Cf. COMAROFF, John L.; ROBERTS, Simon. Rules and processes: the cultural logic of dispute in an African context. Chicago: University of Chicago Press, 1986. p. 8-10. Para uma excelente resenha crítica da obra de Comaroff e Roberts, ver: LE ROY, Étienne. J. L. Comaroff and S. Roberts. Rules and processes. The cultural logic of dispute in an African context. Chicago and London, University of Chicago Press, 1981 - Book Review. Journal of Legal Pluralism and Unofficial Law, n. 21, p. 155-157, 1983. Como exemplo do paradigma processual, ver: MALINOWSKI, Bronislaw. Crime and custom in savage society. 7. ed. London: Routledge \& Kegan Paul, 1961. Como exemplo do paradigma normativo, ver: RADCLIFFE-BROWN, Alfred Reginald. Structure and function in primitive society. London: Cohen \& West, 1952.

9 A respeito, ver, por exemplo: CLASTRES, Pierre. La société contre l'État. Recherches d'anthropologie politique. Paris: Les Éditions du Minuit, 2011. p. 15-16 e 19; LÉVI-STRAUSS, Claude. Race et histoire. Paris: Denoël, 1987. p. 19-26. No que concerne à questão do etnocentrismo pelo ângulo específico da antropologia do direito, ver, por exemplo: EBERHARD, Christoph. Para uma teoria jurídica intercultural o desafio dialógico. Revista Direito e Democracia, v. 3, n. 2, p. 497 e ss., jul.-dez. 2002; LE ROY, Étienne. La terre de l'autre. Une anthropologie des régimes d'appropriation foncière. Paris: LGDJ, 2011. p. 26; ROULAND, Norbert. Anthropologie juridique, p. 37-40; SHIRLEY, Robert Weaver. Antropologia jurídica. São Paulo: Saraiva, 1987. p. 5.

10 Cf. TODOROV, Tzvetan. Nous et les autres. La réflexion française sur la diversité humaine. Paris: Éditions du Seuil, 1989. p. 21-22.

11 Cf. LÉVI-STRAUSS, Claude. Race et histoire, p. 20. A esse respeito, Pierre Clastres relacionava etnocentrismo e etnocídio, enfatizando que se toda cultura é etnocêntrica, somente a ocidental seria etnocida. Cf. CLASTRES, Pierre. Arqueologia da violência. Pesquisas de antropologia política. Tradução de Paulo Neves. São Paulo: Cosac \& Naify, 2004. p. 86.

12 Ao insistir na anulação que o etnocentrismo faz da diferença, sublinhando, assim, sua incompatibilidade com a questão a alteridade, Pierre Clastres menciona que “l'ethnocentrisme n'est donc pas une vaine entrave à la réflexion et ses implications sont de plus de conséquence qu'on ne pourrait croire. Il ne peut laisser des différences chacune pour soi en sa neutralité, mais veut les comprendre comme différences déterminées à partir de ce qui est le plus familier, le pouvoir tel qu'il est éprouvé et pensé dans la culture de l'Occident. [...] L'obstacle épistémologique que la 'politicologie' n'a pas su jusqu'à présent surmonter, nous avons cru le déceler dans l'ethnocentrisme culturel de la pensée occidentale [...]" (CLASTRES, Pierre. La société contre l'État, p. 16 e 19). 
enquanto tal, deveria ser objeto de uma constante "vigilância epistemológica". ${ }^{13}$ Aliás, para além da dimensão epistemológica, Laura Nader e Ugo Mattei ressaltam o quanto a configuração etnocêntrica das instituições e dos sistemas de crenças e de valores também serve de reforço à imposição da ideia de "rule of law" em projetos de perfil colonial e imperial de potências ocidentais. ${ }^{14}$

Trata-se, portanto, de um problema da mais alta relevância, cujos entraves epistemológicos podem comprometer uma compreensão intercultural do "fenômeno jurídico". Diante do homeomorfismo que perpassa as culturas jurídicas, surge o problema relativo à utilização de categorias e termos jurídicos ocidentais para a análise dos sistemas jurídicos das sociedades tradicionais. De um lado, Paul Bohannan considerava que essa prática de utilização de termos e conceitos jurídicos próprios das sociedades ocidentais para a análise comparativa com outras culturas deveria ser proscrita, de modo que os antropólogos deveriam privilegiar a análise das criações culturais, sociais e jurídicas próprias da sociedade que ele estuda, as quais comporiam o que ele denomina de folk system. ${ }^{15}$ De outro lado, Max Gluckman, sustentava que a posição de Bohannan poderia, no limite, inviabilizar a comparação entre culturas, ${ }^{16}$ motivo pelo qual utilizava em sua análise de outras culturas jurídicas, em especial dos Barotse que constituíram seu objeto

13 Conforme ressaltam Pierre Bourdieu, Jean-Claude Chamboredon e Jean-Claude Passeron, "les mises en garde contre l'ethnocentrisme sont de peu de poids si elles ne sont sans cesse ravivées et réinterprétées par la vigilance épistémologique" (BOURDIEU, Pierre; CHAMBOREDON, Jean-Claude; PASSERON, Jean-Claude. Le métier de sociologue. 5. ed. Berlin: Mouton de Gruyter, 2005. p. 100). Sobre essa questão, ver, por exemplo: JOURDAIN, Anne; NAULIN, Sidonie. La théorie de Pierre Bourdieu et ses usages sociologiques. Paris: Armand Colin, 2011. p. 17 e ss. Para uma análise da obra Le métier de sociologue e à crítica de Bourdieu ao "etnocentrismo metodológico" de Barton e Lazarsfeld, ver: LEBARON, Frédéric. Le métier de sociologue. Préalables épistémologiques. In: LEBARON, Frédéric; MAUGER, Gérard (Dir.) Lectures de Bourdieu. Paris: Ellipses, 2012. p. 111-121.

14 Cf. NADER, Laura; MATTEI, Ugo. Plunder: when the rule of law is illegal. Oxford: Blackwell Publishing, 2008. p. 1,3 e 17.

15 Conforme se verá adiante, Bohanann designa de folk system a estruturação da experiência feita pelo etnógrafo a partir das categorias nativas que estão sendo analisadas. Trata-se, assim, da interpretação orientada para a ação que se funda na experiência etnográfica. Cf. BOHANNAN, Paul. Ethnography and comparison in legal anthropology. In: NADER, Laura (Ed.). Law in culture and society. Berkeley, California: University of California Press, 1997. p. 405 e ss. A respeito, ver também: DAVIS, Shelton H. Introdução. In:

(Org.). Antropologia do direito: estudo comparativo de categorias de dívida e contrato. Tradução de Vera Maria Cândido Pereira. Rio de Janeiro: Zahar, 1973. p. 21-22. Na coletânea organizada por Shelton H. Davis, o termo é esdruxulamente traduzido para o português como "sistema de folk". Optou-se aqui por manter a expressão folk system no original, mesmo considerando que ela poderia ser traduzida como "sistema popular", tal como o faz Jacques Vanderlinden com a expressão système populaire. Cf. VANDERLINDEN, Jacques. Anthropologie juridique. Paris: Dalloz, 1996. p. 87.

16 Cf. GLUCKMAN, Max. Obrigação e dívida. In: DAVIS, Shelton H. (Org.). Antropologia do direito: estudo comparativo de categorias de dívida e contrato. Tradução de Vera Maria Cândido Pereira. Rio de Janeiro: Zahar, 1973. p. 37. (Cumpre notar que esse texto que aparece na coletânea de Davis consiste numa parte do livro The ideas in Barotse Jurisprudence, publicado em 1965.) 
direto de estudo, os instrumentos conceituais extraídos do vocabulário dos historiadores do direito inglês. ${ }^{17}$

Essa discussão foi introduzida no Brasil no início dos anos 70, em grande medida pelos esforços de Shelton H. Davis, responsável pela organização de uma excelente coletânea de textos, intitulada "Antropologia do direito: estudo comparativo de categorias de dívida e contrato", publicada em português, em 1973, e que reuniu escritos importantes de Max Gluckman, Paul Bohannan, Edmund R. Leach, Conrad Arensberg e Solon Kimball. ${ }^{18}$ Apesar de sua relevância, essa discussão não recebeu o impacto merecido entre nós, sendo, quando muito, aludida lateralmente nas análises que aqui são feitas. Tudo se passa como se pudéssemos considerá-la superada, sem, entretanto, a termos efetivamente assimilado. ${ }^{19}$ Contudo, os reflexos dessa lacuna são perceptíveis nas deficiências que, por vezes, se explicitam em abordagens antropológicas feitas acerca do direito no Brasil. Desse modo, visando contribuir para a análise do problema epistemológico de grande relevo que perpassa a questão relativa a como desenvolver a comparação entre culturas jurídicas homeomorfas, será feita a seguir uma breve reconstrução dos aspectos essenciais que pautaram a célebre discussão de Max Gluckman e Paul Bohannan. Para tanto, será enfocada, em primeiro lugar, a posição de Gluckman acerca da comparação. Em segundo lugar, será abordada a posição de Bohannan, em especial a partir de sua ênfase na especificidade do que ele denomina de folk systems. Em seguida, será feita uma alusão pontual a alguns reflexos dessa controvérsia clássica no debate antropológico atual. Por fim, uma breve conclusão procurará sublinhar os impasses que emergem do antagonismo entre os dois autores.

17 GLUCKMAN, Max. Obrigação e dívida. In: DAVIS, Shelton H. (Org.). Antropologia do direito: estudo comparativo de categorias de dívida e contrato. Tradução de Vera Maria Cândido Pereira. Rio de Janeiro: Zahar, 1973. p. 29.

18 Cabe aqui sublinhar a contribuição de Shelton H. Davis não apenas ao desenvolvimento da antropologia jurídica no Brasil, mas também à discussão relativa ao papel do Estado brasileiro em relação aos povos indígenas. A respeito, ver: DAVIS, Shelton H. Victims of the miracle: development and the Indians of Brazil. New York: Cambridge University Press, 1977. Acerca da importância dessa obra de Shelton H. Davis, ver, por exemplo: HEMMING, John. Die if you must. Brazilian Indians in the Twentieth Century. London: Macmillan, 2003. p. 219; VILLAS BÔAS FILHO, Orlando. História, direito e a política indigenista brasileira no século XX. In: VILLAS BÔAS FILHO, Orlando (Org.). Orlando Villas Bôas: expedições, reflexões e registros. São Paulo: Metalivros, 2006. p. 58; VILLAS BÔAS FILHO, Orlando. Os direitos indígenas no Brasil contemporâneo. In: BITTAR, Eduardo Carlos Bianca. História do direito brasileiro: leituras da ordem jurídica nacional. São Paulo: Atlas, 2003. p. 279-293; VILLAS BÔAS FILHO, Orlando. A construção do campo indigenista no Brasil. In: VILLAS BÔAS FILHO, Orlando (Org.). Orlando Villas Bôas e a construção do indigenismo no Brasil. São Paulo: Editora Mackenzie, 2014. p. 153-154.

19 Aliás, referindo-se à divergência entre as perspectivas de Bohannan e Gluckman, Jacques Vanderlinden enfatiza que "la discussion [...] dure encore et n'est pas prête à s'éteindre" (VANDERLINDEN, Jacques. Anthropologie juridique. Paris: Dalloz, 1996. p. 88). 
1. Max Gluckman e o problema da comparação entre culturas jurídicas distintas

Max Gluckman, em livros como The judicial process among the Barotse of Northern Rhodesia, publicado originalmente em 1955 e republicado, com correções e acréscimos, em 1967, e The ideas in Barotse Jurisprudence, publicado em 1965, desenvolveu um importante estudo antropológico acerca do direito do povo Barotse que habita o território da atual Zâmbia, comparando-o com o direito inglês e utilizando a noção ocidental de dívida como um elemento fundamental para a realização dessa análise comparativa. ${ }^{20}$ Apesar de Gluckman ter realizado seus estudos de campo na África no período colonial, vários de seus influentes trabalhos foram publicados durante as primeiras décadas de independência. Portanto, segundo Sally Falk Moore, ele teria procurado compreender simultaneamente as “duas Áfricas”, ou seja, a do período colonial e a que se apresentava à época dos movimentos de independência. ${ }^{21}$ Trata-se de um autor que teria exercido uma expressiva influência nos estudos antropológicos e jurídicos em meados do século XX. ${ }^{22}$ Aliás, mesmo juristas contemporâneos interessados em realizar grandes generalizações o citam frequentemente para fundamentar a possibilidade de tais empreitadas. ${ }^{23}$

\section{No livro intitulado The Judicial Process among the Barotse of Northern} Rhodesia, Max Gluckman, fundador da chamada escola de Manchester, propunha, pela primeira vez, uma descrição detalhada do modo pelo qual ocorriam os processos decisórios nos tribunais dos Barotse. Com o intuito de contextualizar a obra de Gluckman e aquilatar as inovações por ela trazidas no momento de sua publicação em 1955, Sally Falk Moore

20 Nesse particular, cabe notar que, conforme observam María Teresa Sierra e Victoria Chenaut, Gluckman distingue entre os Lozi (grupo dominante do reino Barotse) e as tribos vizinhas às quais ele se refere como Barotse. Seu livro The ideas in Barotse Jurisprudence trata principalmente da tribo Lozi que, a partir de 1900, subordinou-se ao protetorado britânico e ao governo indireto que caracterizava a dominação da Grã-Bretanha. Cf. SIERRA, María Teresa; CHENAUT, Victoria. Los debates recientes y actuales en la antropología jurídica: las corrientes anglosajonas. In: KROTZ, Esteban (Ed.). Antropología jurídica: perspectivas socioculturales en el estudio del derecho. Rubí (Barcelona): Anthropos Editorial; México: Universidad Autónoma Metropolitana - Iztapalapa, 2002. p. 122.

21 Cf. MOORE, Sally Falk. Certainties undone: fifty turbulent years of legal anthropology, 1949-1999. The Journal of the Royal Anthropological Institute, London, v. 7, n. 1, Mar. 2001. p. 98.

22 Cf. MOORE, Sally Falk. Certainties undone: fifty turbulent years of legal anthropology, 1949-1999. The Journal of the Royal Anthropological Institute, London, v. 7, n. 1, p. 95-116, Mar. 2001; (o artigo também está disponível em: MOORE, Sally Falk. Law and anthropology: a reader. Malden/USA: Blackwell, 2005. p. 346-367). Em The concept of law, Hart, ao analisar o modo pelo qual as disputas são resolvidas em "sociedades primitivas", por ele caracterizadas por deterem formas rudimentares de adjudicação em virtude da inexistência de sanções organizadas a partir de um sistema central, alude à noção de "anarquia organizada", proposta por Evans-Pritchard acerca dos Nuer. Contudo, curiosamente, não o faz diretamente, e sim a partir de uma citação de Gluckman em The judicial process among the Barotse. Cf. HART, Herbert L. A. The concept of law. 2. ed. Oxford: Clarendon Press, 1994. p. 291-292.

23 Cf. LOSANO, Mario G. Os grandes sistemas jurídicos: introdução aos sistemas jurídicos europeus e extraeuropeus. Tradução de Marcela Varejão. São Paulo: Martins Fontes, 2007. p. 352. 
a compara com a clássica análise desenvolvida por Llewellyn e Hoebel no livro The Cheyenne Way, publicado em 1941. Segundo a autora, diferentemente do que ocorria na análise de Llewellyn e Hoebel, a de Gluckman fundava-se não em casos relatados por informantes, mas na observação direta do modo como eram decididos nos tribunais Barotse (Kutas) ${ }^{24}$ A partir de sua observação direta acerca dos casos levados aos Kutas, Gluckman focalizava as regras e o raciocínio que embasavam as decisões, concluindo que os juízes Barotse decidiriam a partir de princípios lógicos encontrados em quaisquer tribunais. Segundo ele, apesar de partirem de premissas diferentes, a lógica e o processo de raciocínio dos juízes Barotse seriam análogos aos de seus sucedâneos ocidentais. ${ }^{25}$ Diante disso, Gluckman sustentava que os juízes Barotse aplicariam o padrão do homem razoável (the standard of the 'Reasonable Man'). ${ }^{26}$

Sally Falk Moore ressalta, ainda, a ênfase dada por Gluckman à questão da comparação. Para tanto, observa que, segundo ele, alguns conceitos dos Barotse seriam característicos de sociedades com baixos níveis de tecnologia, economia simples e uma ordem sociopolítica rudimentar. Nesse sentido, sustenta que a perspectiva de Gluckman expressaria a postura de um antropólogo que, apesar de estar politicamente interessado em defender os africanos, interpretaria seus sistemas sociais e seus conceitos políticos como portadores de um resíduo substancial de uma economia pré-capitalista e arcaica. ${ }^{27}$

De fato, Gluckman, ao desenvolver sua análise comparativa, sublinha que os Barotse descreveriam todas as suas relações em termos de dívida, tal como ocorreria no direito ocidental antigo. ${ }^{28}$ Baseando-se nas análises de William Seagle acerca das

24 Cf. MOORE, Sally Falk. Law as process. An anthropological approach. Hamburg: LIT, 2000. p. 225; MOORE, Sally Falk. Certainties undone: fifty turbulent years of legal anthropology, 1949-1999. The Journal of the Royal Anthropological Institute, London, v. 7, n. 1, Mar. 2001. p. 99.

25 Cf. MOORE, Sally Falk. Certainties undone: fifty turbulent years of legal anthropology, 1949-1999. The Journal of the Royal Anthropological Institute, London, v. 7, n. 1, Mar. 2001. p. 98-99; NADER, Laura. The life of the law: anthropological projects. Berkeley: University of California Press, 2002. p. 25-26. A respeito, ver também: OLIVEIRA, Luís Roberto Cardoso de. A dimensão simbólica dos direitos e a análise de conflitos. Revista de Antropologia da USP, São Paulo, v. 53, n. 2, jul.-dez. 2010. p. 465; OLIVEIRA, Luís Roberto Cardoso de. Moral e ética. In: SOUZA LIMA, Antonio Carlos de (Coord.). Antropologia \& Direito: temas antropológicos para estudos jurídicos. Brasília/Rio de Janeiro/Blumenau: Associação Brasileira de Antropologia/Laced/Nova Letra, 2012. p. 96-97.

26 Cf. GLUCKMAN, Max. The judicial process among the Barotse of Northern Rhodesia (Zambia). 2. ed. Manchester: Manchester University Press, 1973. p. 83. Para uma discussão acerca da noção de Reasonable Man no pensamento de Gluckman, ver: MOORE, Sally Falk. Law as process. An anthropological approach. Hamburg: LIT, 2000. p. 226; PEÑA, Guillermo de la. Costumbre, ley y procesos judiciales en la antropología clásica: apuntes introductorios. In: KROTZ, Esteban. (Ed.) Antropología jurídica: perspectivas socioculturales en el estudio del derecho. Rubí (Barcelona): Anthropos Editorial; México: Universidad Autónoma Metropolitana - Iztapalapa, 2002. p. 66.

27 Cf. MOORE, Sally Falk. Certainties undone: fifty turbulent years of legal anthropology, 1949-1999. The Journal of the Royal Anthropological Institute, London, v. 7, n. 1, Mar. 2001. p. 98-99.

28 Cf. GLUCKMAN, Max. Obrigação e dívida. In: DAVIS, Shelton H. (Org.). Antropologia do direito: estudo comparativo de categorias de dívida e contrato. Tradução de Vera Maria Cândido Pereira. Rio de Janeiro: 
peculiaridades dos direitos babilônico, grego e romano, Gluckman acentua que a dívida seria uma obrigação concebida em termos de propriedade, que teria predominado no direito romano antigo, tal como ocorreu no direito inglês. Seguindo Seagle, Gluckman enfatiza que a ideia de contrato pressuporia o início das transações de crédito, troca, empréstimo etc., de modo que, antes disso, mais do que a ideia de um compromisso contratual rompido, o que teria havido seria a ideia de uma violação (de um logro) de direitos que deveria ser punida. ${ }^{29}$

Partindo dessa premissa, Gluckman considera ser possível descrever o direito dos Barotse em termos de dívida. E, para fazer isso, ele ressalta que haveria dois excelentes estudos etnográficos acerca da dívida em sociedades nas quais a autoridade seria "pouco desenvolvida". Dentre tais estudos, destaca o de Edmund Leach (The political system of highland Burma, publicado em 1954) e o de Paul Bohannan (Justice and judgment among the Tiv of Nigeria, publicado em 1957). ${ }^{30}$

No que se refere ao estudo de Edmund Leach, Gluckman destaca sua análise da categoria $h k a$ dos Kachin da Birmânia, categoria essa que traduz como dívida. Assim, Gluckman observa que, segundo Leach, entre os Kachin, quase todos os tipos de obrigação legais poderiam ser descritos em termos de dívida $(h k a) .{ }^{31}$ Haveria, desse modo, uma lista de objetos (denominados de riqueza comercial ou ritual) que deveriam ser dados em pagamento no caso de infração a alguma regra estabelecida pelo grupo. Assim, na ocorrência de alguma infração, haveria, inclusive, "intermediários" que barganhariam

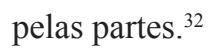

Gluckman também observa que, segundo Leach, para os Kachin, as reivindicações legais e comerciais seriam igualmente categorizadas como hka. Assim, as punições entre os Kachin variariam de acordo com o status dos indivíduos. Essa diferença de status se refletiria no tipo e na quantidade de objetos rituais que deveriam ser dados

Zahar, 1973. p. 25.

29 Cf. GLUCKMAN, Max. Obrigação e dívida. In: DAVIS, Shelton H. (Org.). Antropologia do direito: estudo comparativo de categorias de dívida e contrato. Tradução de Vera Maria Cândido Pereira. Rio de Janeiro: Zahar, 1973. p. 26-27.

30 Cf. GLUCKMAN, Max. Obrigação e dívida. In: DAVIS, Shelton H. (Org.). Antropologia do direito: estudo comparativo de categorias de dívida e contrato. Tradução de Vera Maria Cândido Pereira. Rio de Janeiro: Zahar, 1973. p. 29.

31 Cf. GLUCKMAN, Max. Obrigação e dívida. In: DAVIS, Shelton H. (Org.). Antropologia do direito: estudo comparativo de categorias de dívida e contrato. Tradução de Vera Maria Cândido Pereira. Rio de Janeiro: Zahar, 1973. p. 29-30.

32 A esse respeito, Gluckman ressalta que "as negociações são feitas pelos que Leach chama de 'agentes dos implicados'. Mas como essa expressão pode gerar confusão com a situação moderna dos contratos de representação, eu os chamarei de 'intermediários'." GLUCKMAN, Max. Obrigação e dívida. In: DAVIS, Shelton H. (Org.). Antropologia do direito: estudo comparativo de categorias de dívida e contrato. Tradução de Vera Maria Cândido Pereira. Rio de Janeiro: Zahar, 1973. p. 30. 
como reparação de uma infração. ${ }^{33}$ Afirma, portanto, que "esses objetos rituais variam com a natureza da ofensa e com o status das partes. Punições por engravidar uma mulher solteira variam com o status da mulher e do homem. Se um homem rouba um búfalo de outro, ele deve devolvê-lo e mais um outro de compensação, além de três objetos rituais $[\ldots]^{\prime} \cdot 34$

Logo, Gluckman assevera que a análise de Leach apontaria para o fato de que todas as relações entre os Kachin poderiam ser colocadas como parte de um sistema de dívidas, ${ }^{35}$ em meio ao qual as dívidas não saldadas ensejariam conflitos, de modo que, havendo uma tal situação, o credor teria a desculpa legítima de recorrer à violência. ${ }^{36}$ As dívidas entre os Kachin ocorreriam não apenas entre indivíduos, mas entre facções e linhagens, de modo que uma dívida não saldada passaria de geração para geração. Essa digressão feita pelo estudo de Leach tem uma razão de ser. Visa fornecer esteio ao argumento relativo à universalidade da categoria "dívida" nas sociedades "arcaicas". Neste sentido, Gluckman ressalta que:

Apresentei esse resumo, porque ele mostra como uma tribo geográfica e culturalmente distante dos Barotse tem a mesma idéia de dívida presente no direito Barotse. [...] Entre os Kachin há nitidamente um alto grau de especificidade nas relações sociais dentro de uma situação economicamente indiferenciada, dominada por laços de status. Cada relação tem atributos específicos, marcados por modos de comportamento convencionais (que Leach chama de "rituais") e cada relação implica uma série de dívidas interligadas que devem ser ajustadas pelo pagamento de objetos específicos. [...] Portanto, a ofensa, ou se insere numa série de dívidas em relações de status já existentes, ou cria uma relação semelhante à relação de status [...]. Também nesse caso, como entre os Barotse, encontramos que a ênfase do direito Kachin reside nas convenções, tanto de comportamento quanto de direitos à propriedade, que distinguem cada relação de status. Confere-se, portanto,

33 Cf. GLUCKMAN, Max. Obrigação e dívida. In: DAVIS, Shelton H. (Org.). Antropologia do direito: estudo comparativo de categorias de dívida e contrato. Tradução de Vera Maria Cândido Pereira. Rio de Janeiro: Zahar, 1973. p. 31.

34 GLUCKMAN, Max. Obrigação e dívida. In: DAVIS, Shelton H. (Org.). Antropologia do direito: estudo comparativo de categorias de dívida e contrato. Tradução de Vera Maria Cândido Pereira. Rio de Janeiro: Zahar, 1973. p. 31.

35 Cf. GLUCKMAN, Max. Obrigação e dívida. In: DAVIS, Shelton H. (Org.). Antropologia do direito: estudo comparativo de categorias de dívida e contrato. Tradução de Vera Maria Cândido Pereira. Rio de Janeiro: Zahar, 1973. p. 32.

36 Cf. GLUCKMAN, Max. Obrigação e dívida. In: DAVIS, Shelton H. (Org.). Antropologia do direito: estudo comparativo de categorias de dívida e contrato. Tradução de Vera Maria Cândido Pereira. Rio de Janeiro: Zahar, 1973. p. 33. 
um grande valor às transações com propriedades, como indicador de direitos e deveres de status. [...] É esse o significado da dívida numa sociedade tribal. ${ }^{37}$

No que tange ao estudo de Bohannan, realizado entre os Tiv da Nigéria, Gluckman ressalta que ele também serviria para indicar o predomínio da ideia de dívida no direito tribal. ${ }^{38}$ Para tanto, critica a conclusão de Bohannan segundo a qual essa característica daria ao sistema Tiv um caráter único que não poderia ser examinado em termos dos conceitos da "ciência do direito ocidental". ${ }^{39}$ Gluckman, referindo-se à perspectiva de Bohannan, ressalta que não põe em questão a importância de se descrever com precisão as ideias de outro povo, ou seja, seu folk system. Sua crítica dirige-se ao que considera ser uma tendência solipsista que decorria de tal perspectiva ${ }^{40}$ que, em seu entendimento, engendraria dois problemas: a) a possibilidade de comparação entre sistemas legais distintos; b) sendo possível a comparação, em que termos realizá-la de modo a não distorcer os sistemas legais..$^{41}$

De fato, referindo-se à questão da dívida, Bohannan enfatiza que os Tiv não estabeleceriam as distinções europeias existentes, por exemplo, entre danos que afetam toda a comunidade e danos que atingem só os indivíduos. Nesse sentido, a distinção europeia a esse respeito seria, em seu entendimento, uma mera folk distinction. Assim, segundo ele, poder-se-iam comparar as distinções realizadas pelos europeus e pelos Tiv,

37 GLUCKMAN, Max. Obrigação e dívida. In: DAVIS, Shelton H. (Org.). Antropologia do direito: estudo comparativo de categorias de dívida e contrato. Tradução de Vera Maria Cândido Pereira. Rio de Janeiro: Zahar, 1973. p. 34-35.

38 Cf. GLUCKMAN, Max. Obrigação e dívida. In: DAVIS, Shelton H. (Org.). Antropologia do direito: estudo comparativo de categorias de dívida e contrato. Tradução de Vera Maria Cândido Pereira. Rio de Janeiro: Zahar, 1973. p. 35.

39 Cf. GLUCKMAN, Max. Obrigação e dívida. In: DAVIS, Shelton H. (Org.). Antropologia do direito: estudo comparativo de categorias de dívida e contrato. Tradução de Vera Maria Cândido Pereira. Rio de Janeiro: Zahar, 1973. p. 36.

40 Assim, referindo-se a Bohannan, Gluckman sublinha que "ele começa por insistir, corretamente, em que se descreva com precisão as ideias de um povo, o que ele chama de seu 'sistema de folk'. Mas insiste, ainda [...] em que: 'o erro principal da análise etnográfica e social [...] é o de elevar sistemas de folk, como o 'direito', destinado à ação social em nosso próprio sistema, ao status de um sistema analítico, e depois tentar organizar os dados brutos de outras sociedades dentro dessas categorias. Eu [Bohannan] também tentei evitar o erro equivalente de colocar os sistemas de folk dos romanos ou dos trobriandeses ao nível de um sistema analítico para dados que talvez não se encaixem neles" (GLUCKMAN, Max. Obrigação e dívida. In: DAVIS, Shelton H. (Org.). Antropologia do direito: estudo comparativo de categorias de dívida e contrato. Tradução de Vera Maria Cândido Pereira. Rio de Janeiro: Zahar, 1973. p. 36; MOORE, Sally Falk. Law as process. An anthropological approach. Hamburg: LIT, 2000. p. 227; NADER, Laura. The anthropological study of law. American Anthropologist, Arlington, v. 67, n. 6, p. 3-32, Dec. 1965.

${ }^{41}$ Gluckman refere-se a isso do seguinte modo: "essa questão levanta dois problemas separados: primeiro, se é possível comparar-se sistemas legais diferentes; e, segundo, se for possível fazer comparação, em que linhagem de termos pode-se fazê-la sem distorcer os sistemas legais?" GLUCKMAN, Max. Obrigação e dívida. In: DAVIS, Shelton H. (Org.). Antropologia do direito: estudo comparativo de categorias de dívida e contrato. Tradução de Vera Maria Cândido Pereira. Rio de Janeiro: Zahar, 1973. p. 36. 
mas seria equivocado e parcial tentar encaixar as categorizações dos Tiv nas que são próprias ao direito europeu, assim como também o seria realizar o inverso. ${ }^{42}$

Contudo, diante disso, Gluckman ressalta que, baseado em tais premissas, Bohannan não seria capaz de explicar se se pode comparar ou o que se pode comparar dentro de dois conjuntos de distinções. ${ }^{43}$ Segundo Gluckman, a insistência de Bohannan na especificidade cultural dos folk systems desviaria a atenção das semelhanças dentro de diferenças, obscurecendo a análise de questões relativas ao direito numa dada sociedade e no âmbito do direito comparado. ${ }^{44}$ Nesse sentido, para Gluckman, a posição de Bohannan poderia criar uma barreira à análise sociológica e à ciência do direito. ${ }^{45}$

Gluckman alude, por exemplo, ao fato de Bohannan enfatizar que a noção de dívida (injô) utilizada pelos Tiv não coincide com a europeia. A esse respeito, Bohannan sustenta que a categoria "dívida" (injô) dos Tiv referir-se-ia a circunstâncias e casos que em nosso folk system seriam classificados a partir de várias categorias. ${ }^{46}$ Contudo, segundo Gluckman, se assim é, em última análise, a perspectiva de Bohannan não permitiria esclarecer o que noções como injô significam. ${ }^{47}$ Desse modo, Gluckman considera que a descrição de um folk system de ideias legais seria apenas o primeiro passo da análise. A partir daí dever-se-ia tentar relacionar as particularidades de um folk system aos outros elementos do sistema social, o que implicaria realizar comparações de conjuntos de ideias legais em sociedades diferentes. ${ }^{48}$ É nesse sentido que Gluckman critica o "solipsismo cultural" engendrado pela análise de Bohannan. ${ }^{49}$

42 A respeito, ver: BOHANNAN, Paul. Justice and judgment among the Tiv, p. 119-120, apud GLUCKMAN, Max. Obrigação e dívida. In: DAVIS, Shelton H. (Org.). Antropologia do direito: estudo comparativo de categorias de dívida e contrato. Tradução de Vera Maria Cândido Pereira. Rio de Janeiro: Zahar, 1973. p. 36.

43 Cf. GLUCKMAN, Max. Obrigação e dívida. In: DAVIS, Shelton H. (Org.). Antropologia do direito: estudo comparativo de categorias de dívida e contrato. Tradução de Vera Maria Cândido Pereira. Rio de Janeiro: Zahar, 1973. p. 37.

44 Cf. GLUCKMAN, Max. Obrigação e dívida. In: DAVIS, Shelton H. (Org.). Antropologia do direito: estudo comparativo de categorias de dívida e contrato. Tradução de Vera Maria Cândido Pereira. Rio de Janeiro: Zahar, 1973. p. 38.

45 Cf. GLUCKMAN, Max. Obrigação e dívida. In: DAVIS, Shelton H. (Org.). Antropologia do direito: estudo comparativo de categorias de dívida e contrato. Tradução de Vera Maria Cândido Pereira. Rio de Janeiro: Zahar, 1973. p. 39.

46 Cf. GLUCKMAN, Max. Obrigação e dívida. In: DAVIS, Shelton H. (Org.). Antropologia do direito: estudo comparativo de categorias de dívida e contrato. Tradução de Vera Maria Cândido Pereira. Rio de Janeiro: Zahar, 1973. p. 40.

${ }^{47}$ Cf. GLUCKMAN, Max. Obrigação e dívida. In: DAVIS, Shelton H. (Org.). Antropologia do direito: estudo comparativo de categorias de dívida e contrato. Tradução de Vera Maria Cândido Pereira. Rio de Janeiro: Zahar, 1973. p. 41.

48 Cf. GLUCKMAN, Max. Obrigação e dívida. In: DAVIS, Shelton H. (Org.). Antropologia do direito: estudo comparativo de categorias de dívida e contrato. Tradução de Vera Maria Cândido Pereira. Rio de Janeiro: Zahar, 1973. p. 46.

49 Segundo Gluckman, "torna-se claro que a descrição de um sistema de folk de ideias legais, conforme aconselhado por Bohannan, é apenas um passo da análise. A partir daí, deve-se tentar relacionar as 
Em diversos momentos, Gluckman critica a insistência de Bohannan em apontar a especificidade do sistema Tiv com intuito de ressaltar sua distinção radical do sistema ocidental. No que concerne à categoria injô, Bohannan, procurando sublinhar sua singularidade, desenvolve meticulosas análises visando enfatizar que ela não coincidiria com as categorias ocidentais de contrato e relação não contratual. Gluckman, entretanto, ressalta as semelhanças entre tal categoria com as análogas desenvolvidas entre os Kachin da Birmânia e os Barotse da Zâmbia. ${ }^{50}$ Alude, inclusive, à afirmação de Malinowski a respeito da existência, no que se poderia denominar de direito da Oceania, de um sistema de obrigações recíprocas que produziriam uma "rede de dívidas" ${ }^{51} \mathrm{Com}$ isso, sua intenção é mobilizar elementos que o permitam rejeitar a tese da singularidade das categorias existentes entre os Tiv.

Assim, Gluckman esforça-se em mostrar a existência de analogias entre as categorias mobilizadas pelos Tiv, especialmente a de injô, e o modo de raciocínio envolvido nas ações antigas do direito inglês, romano, chinês e do oriente próximo que, segundo ele, se refeririam basicamente a dívidas. Sua intenção é aproximar o que os Tiv categorizam como injô (e Bohannan traduz como dívida) e o princípio que orientaria as ações no direito ocidental antigo. Bohannan, ao sustentar que os Tiv não fariam a distinção entre obrigações contratuais e não contratuais, procura mostrar a impossibilidade de projetar sobre eles tais categorias ocidentais. ${ }^{52}$ Gluckman, apoiando-se nas análises clássicas de Herbert Felix Jolowicz e Henry J. Sumner Maine, enfatiza que também no direito ocidental as noções de obrigação ex contractu e ex delicto não teriam sido claramente percebidas

particularidades de um sistema folk aos outros elementos do sistema social. Isso implica necessariamente comparações de conjuntos de ideias legais em sociedades diferentes, sobre as quais temos dados históricos a respeito do desenvolvimento de conjuntos particulares dessas ideias" (Cf. GLUCKMAN, Max. Obrigação e dívida. In: DAVIS, Shelton H. (Org.). Antropologia do direito: estudo comparativo de categorias de dívida e contrato. Tradução de Vera Maria Cândido Pereira. Rio de Janeiro: Zahar, 1973. p. 47).

50 Gluckman enfatiza que "O injô dos Tiv, o conceito das obrigações materiais em relações de status ou quase status é, portanto, semelhante ao que os Barotse chamam de Bung'a, propriedade, e os Kachin, de $h k a$. Reflete o estreito envolvimento dos direitos de propriedade com relações de status" (Cf. GLUCKMAN, Max. Obrigação e dívida. In: DAVIS, Shelton H. (Org.). Antropologia do direito: estudo comparativo de categorias de dívida e contrato. Tradução de Vera Maria Cândido Pereira. Rio de Janeiro: Zahar, 1973. p. 45).

51 Cf. GLUCKMAN, Max. Obrigação e dívida. In: DAVIS, Shelton H. (Org.). Antropologia do direito: estudo comparativo de categorias de dívida e contrato. Tradução de Vera Maria Cândido Pereira. Rio de Janeiro: Zahar, 1973. p. 46.

52 Segundo Bohannan, "os Tiv usam um único conceito, 'dívida' (injô), para se referirem a circunstâncias e casos que nós, em nosso sistema de folk, classificamos em diversas categorias. [...] Nem é preciso dizer que nossas categorias de contrato e de relação não contratual não coincidem exatamente com a categoria Tiv de dívida" (BOHANNAN, Paul. A categoria injô na sociedade Tiv. In: DAVIS, Shelton H. (Org.). Antropologia do direito: estudo comparativo de categorias de dívida e contrato. Tradução de Vera Maria Cândido Pereira. Rio de Janeiro: Zahar, 1973. p. 68-69). Cumpre notar que esse texto constitui um extrato do livro Justice and judgment among the Tiv, publicado em 1957. 
antes do século XIX. ${ }^{53}$ Trata-se, segundo ele, de uma distinção que teria começado no direito das sociedades industriais, ${ }^{54} \mathrm{e}$, se assim é, a alusão a essas noções não pode ser utilizada para afirmar que o sistema ocidental não encontraria paralelo nas categorias do folk system dos Tiv.

Diante disso, a conclusão de Gluckman é que o que Bohannan imagina ser específico do folk system dos Tiv seria encontrado amplamente no direito tribal e também no direito europeu antigo. ${ }^{55}$ Aliás, sobre essa questão, Gluckman ressalta que, embora não seja o caso de forçar a adequação do direito tribal às categorias do direito ocidental, com algum cuidado, seria possível sim realizar comparações a partir dos conceitos ocidentais. ${ }^{56}$ A respeito, numa passagem fortemente expressiva de sua perspectiva e também de sua divergência em relação a Bohannan, Gluckman enfatiza:

I used English words because I was writing in English, and I have always felt that it is unfair to readers to ask them to carry in their heads a large number of vernacular terms. [...] Bohannan uses many Tiv terms. And when he does translate, he sometimes avoids obvious English parallels [...]. Ayoub considers that Bohannan's method makes for greater conceptual clarity than my use of English terms. But in fact Bohannan, since he writes in English, can only avoid the use of a certain number of English jurisprudential terms, such as tort, contract, crime, court, judges. He in fact makes considerable use of English words which

53 Acerca da obra de Henry J. Sumner Maine, ver, por exemplo: VILLAS BÔAS FILHO, Orlando. Ancient law: um clássico revisitado 150 anos depois. Revista da Faculdade de Direito da Universidade de São Paulo, São Paulo, v. 106/107, p. 527-562, jan.-dez. 2011/2012. Para uma análise que alinha Gluckman, Pospisil e Hoebel a Maine, no que concerne ao tratamento de questões universais, ver: NADER, Laura. The anthropological study of law. American Anthropologist, Arlington, v. 67, n. 6, Dec. 1965. p. 7.

54 Segundo Gluckman, "a distinção mais clara entre contratos e relações não contratuais, não desenvolvida mesmo na ciência do direito justiniana, começa a ser feita no direito das sociedades industriais. Portanto, não é de surpreender que os Tiv não fizessem essa distinção" (GLUCKMAN, Max. Obrigação e dívida. In: DAVIS, Shelton H. (Org.). Antropologia do direito: estudo comparativo de categorias de dívida e contrato. Tradução de Vera Maria Cândido Pereira. Rio de Janeiro: Zahar, 1973. p. 48-49).

55 Segundo Moore, "what Gluckman does, further, is to argue that after the notions of an African legal system have been described, they can be compared profitably with those of English law at various stages of its development" (MOORE, Sally Falk. Law as process. An anthropological approach. Hamburg: LIT, 2000. p. 140).

56 A respeito, Gluckman afirma: “[...] procurei mostrar, espero que com êxito, que aquilo que Bohannan encara como um sistema de folk Tiv é encontrado amplamente no direito tribal; e Holmes, Maitland, Seagle e muitos outros juristas afirmaram o mesmo em relação ao direito europeu antigo. É claro que não se deve forçar o direito tribal a adequar-se aos conceitos da ciência do direito ocidental, mas, com algum cuidado, é possível usar esses conceitos refinados para a comparação e análise. A alternativa é inventar uma nova terminologia" (GLUCKMAN, Max. Obrigação e dívida. In: DAVIS, Shelton H. (Org.). Antropologia do direito: estudo comparativo de categorias de dívida e contrato. Tradução de Vera Maria Cândido Pereira. Rio de Janeiro: Zahar, 1973. p. 49). Note-se que Gluckman, em The ideas in Barotse jurisprudence, alude à "textura aberta" dos conceitos jurídicos. A respeito, ver: MOORE, Sally Falk. Law as process. An anthropological approach. Hamburg: LIT, 2000. p. 145. 
have many technical jurisprudential connotations, such as right, duty, obligation, and in the end crime. He explicitly avoids contract and tort because Tiv categorize actions akin to these as "debt". But "debt" itself is a very complex conception: and I have argued in the final chapter of my The Ideas in Barotse Jurisprudence (1965) that we can only understand what this Tiv category of "debt" means if we examine this particular type of categorizing as it occurred in early English law, and a variety of other tribal and early legal systems. I cite this example to show here firstly, that however determined one may be to present a folk-system in its purity, one cannot escape from the use of one's own language. Secondly, it emphasizes that for deeper understanding the presentation solely, allegedly, of the ideas of a folk-system, restricts one's analysis severely. In sociological jurisprudence, comparison puts problems in a more illuminating perspective. I feel therefore that everyone will agree with Bohannan that the first task in reporting a legal system is clearly to describe its "folk-concepts". I consider that very many of these concepts can, without distortion after careful and perhaps lengthy description and discussion, be given English equivalents, at least out of courtesy to one's readers. But some such step is essential at the next stage, when one essays comparative work, unless, as Ayoub seems to favour, one invents neologisms. ${ }^{57}$

A longa citação realizada supra expressa bem o essencial da divergência que opõe Gluckman e Bohannan. Para Sally Falk Moore, a perspectiva de Gluckman revelaria a maneira típica pela qual a antropologia britânica clássica enfocava a África. Era uma tentativa de compreender a África em sua especificidade pré-colonial e as transformações sofridas pela colonização. Sua perspectiva pretendia ser contrária ao etnocentrismo, uma vez que, ao enfocar os padrões de razoabilidade como universais, procurava mostrar que as decisões realizadas nos tribunais africanos eram tão racionais como as que ocorrem nos países ocidentais, ainda que fundadas em premissas distintas. Contudo, apesar de preocupado em sustentar a igualdade racial, Gluckman, ao identificar-se com teorias como de Maine e de Marx, assumia em suas análises um viés evolucionista que o levava a interpretar os sistemas sociais e os conceitos legais dos povos africanos como expressão de resíduos substanciais de uma economia pré-capitalista. ${ }^{58}$

57 GLUCKMAN, Max. The judicial process among the Barotse of Northern Rhodesia (Zambia). 2. ed. Manchester: Manchester University Press, 1973. p. 380-381.

58 Cf. MOORE, Sally Falk. Certainties undone: fifty turbulent years of legal anthropology, 1949-1999. The Journal of the Royal Anthropological Institute, London, v. 7, n. 1, Mar. 2001. p. 98-99. A respeito, ver também: ASSIER-ANDRIEU, Louis. $O$ direito nas sociedades humanas. Tradução de Maria Ermantina Galvão. São Paulo: Martins Fontes, 2000. p. 80. 
De qualquer modo, a contribuição do fundador da escola de Manchester não pode ser subestimada, sobretudo no que concerne ao plano metodológico da descrição. ${ }^{59}$ O livro The Judicial Process among the Barotse, publicado, em sua primeira edição, em 1955, consigna a primeira descrição dos procedimentos realizados num tribunal africano a partir da ótica de um antropólogo que efetivamente os observou. ${ }^{60}$ Para Sally Falk Moore, a obra de Gluckman teria encetado uma revolução no campo metodológico com o direcionamento da análise antropológica para observação direta dos casos, tal como estes ocorrem nos tribunais. ${ }^{61}$ Todavia, conforme se verá a seguir, autores como Bohannan consideram que a perspectiva de Gluckman falsearia a compreensão dos sistemas jurídicos africanos, na medida em que acarretaria uma "ocidentalização falseadora" (a falsifying Westernalization) deles. ${ }^{62}$

Conforme Laura Nader, o que está posto em questão em tal divergência é o problema relativo à autenticidade da análise etnográfica em relação ao direito. ${ }^{63}$ Ou seja, trata-se da questão concernente ao grau de distorção que os antropólogos inevitavelmente introduzem em seus objetos de análise quando os descrevem ou comparam. Além disso, no horizonte de tal debate, coloca-se também em discussão a própria concepção acerca do que é o direito. A respeito, Laura Nader ressalta que

[...] whether we apply Western legal concepts depends on whether we understand law as autonomous or embedded. If, on the one hand, law were independent from society, then law could be universal. Western categories are independent of their original context. On the other hand, if law were

59 Cf. NADER, Laura. The anthropological study of law. American Anthropologist, Arlington, v. 67, n. 6, Dec. 1965. p. 25; MOORE, Sally Falk. Certainties undone: fifty turbulent years of legal anthropology, 19491999. The Journal of the Royal Anthropological Institute, London, v. 7, n. 1, Mar. 2001. p. 99.

60 Cf. MOORE, Sally Falk. Law as process. An anthropological approach. Hamburg: LIT, 2000. p. 225.

${ }^{61}$ A esse respeito, Moore afirma que “the main point about may hasty summary of a few of Gluckman's arguments about law is that he began a revolution in field method with his attention to cases in court. Ever since, local dispute-watching has been the principal form of social voyeurism in legal anthropology" (MOORE, Sally Falk. Certainties undone: fifty turbulent years of legal anthropology, 1949-1999. The Journal of the Royal Anthropological Institute, London, v. 7, n. 1, Mar. 2001. p. 99).

${ }^{62}$ A respeito, ver: NADER, Laura. The anthropological study of law. American Anthropologist, Arlington, v. 67, n. 6, Dec. 1965. p. 11; MOORE, Sally Falk. Certainties undone: fifty turbulent years of legal anthropology, 1949-1999. The Journal of the Royal Anthropological Institute, London, v. 7, n. 1, Mar. 2001. p. 98. Étienne Le Roy aponta três axiomas que, segundo ele, seriam discutíveis na antropologia jurídica anglo-saxã, especialmente na obra de Max Gluckman. Tais axiomas consistiriam em: a) reduzir o Direito a um corpo de regras; b) identificar as regras de Direito apenas a partir do regramento dos conflitos; c) procurar no Direito tanto o respeito de normas coletivas como a expressão de interesses particulares. Cf. LE ROY, Étienne. L'anthropologie juridique anglo-saxonne et l'héritage scientifique de Max Gluckman: un point de vue français. The Journal of Legal Pluralism and Unofficial Law, London, v. 11, n. 17, p. 53-70, 1979.

63 Conforme ressalta Laura Nader, "behind Bohannan's and Gluckman's inquires is a concern for the authenticity of our ethnographies" (NADER, Laura. The life of the law: anthropological projects. Berkeley: University of California Press, 2002. p. 26). 
dependent, then applying Western legal concepts would distort ethnographic data. ${ }^{64}$

\section{Paul Bohannan e a ênfase na especificidade dos folk systems}

Paul Bohannan desenvolveu uma influente análise antropológica do direito em meio à qual se insere seu importante debate com Max Gluckman acerca da comparação entre culturas jurídicas ocidentais e não ocidentais. Um dos aspectos fundamentais desse debate refere-se à questão da universalidade das categorias jurídicas ocidentais e a pertinência de sua utilização na análise comparativa. Não se pretende aqui realizar um exame mais detido da concepção antropológica de Bohannan acerca do direito. As breves alusões que serão feitas a seguir visam apenas introduzir sua perspectiva em relação à questão que está sendo enfocada no presente estudo.

Bohannan considera que a tarefa fundamental da política seria realizar o controle do poder num determinado grupo social territorialmente delimitado. Tal controle seria necessariamente realizado a partir de um conjunto de normas mais ou menos reconhecidas. Desse modo, segundo ele, tradicionalmente, dois conjuntos de atividades seriam representativos da vida política: o direito e a guerra. ${ }^{65}$ Diante dessa assertiva, Bohannan procura distinguir direito e guerra afirmando que o primeiro consistiria numa decisão pacífica realizada no âmbito de um sistema de poder centralizado (unicentric power system), enquanto a guerra expressaria uma decisão violenta realizada num sistema de poder multicêntrico. ${ }^{66}$

Segundo Bohannan, no mundo moderno o Estado desempenharia, internamente, as funções de sucessão e manutenção do poder dentro de limites aceitáveis de desvio normativo. Contudo, os Estados figurariam também como unidades de um sistema multicêntrico em meio ao qual se coloca a questão da soberania. Portanto, o autor enfatiza quatro problemas políticos fundamentais: direito e crime no âmbito de um sistema centralizado (unicentric system) e diplomacia e guerra como problemas de um sistema multicêntrico (multicentric system). ${ }^{67}$ Tais questões são esquematizadas por Bohannan da seguinte maneira.

${ }_{64}$ NADER, Laura. The life of the law: anthropological projects. Berkeley: University of California Press, 2002. p. 26.

65 Cf. BOHANNAN, Paul. Social anthropology. New York: Holt, Rinehart and Winston, 1963. p. 283.

${ }_{66}$ Segundo Bohannan, "'Law' is peaceful decision making in a unicentric power system. 'War' is violent decision in a multicentric power system" (BOHANNAN, Paul. Social anthropology. New York: Holt, Rinehart and Winston, 1963. p. 283).

${ }^{67}$ Cf. BOHANNAN, Paul. Social anthropology. New York: Holt, Rinehart and Winston, 1963. p. 283. Comentando essa distinção de Bohannan, Sally Falk Moore ressalta que "he divides power systems into unicentric dan multicentric types. In unicentric power systems, there is a central locus of legal authority, 
UNICENTRIC AND MULTICENTRIC POWER SYSTEMS ${ }^{68}$

\begin{tabular}{|c|c|c|}
\hline UNICENTRIC & "Law" & $\begin{array}{c}\text { "Police” action against } \\
\text { crime }\end{array}$ \\
\hline MULTICENTRIC & Diplomacy & Warfare \\
\hline
\end{tabular}

Para os propósitos desta análise importa apenas o primeiro dos problemas relacionados por Bohanann, ou seja, o direito. Todavia, não se pretende aqui recuperar, em termos mais detalhados, a concepção antropológica de Bohannan acerca do direito. O que se deseja é apenas indicar sua visão em relação a tal questão para dela extrair os elementos essenciais de seu posicionamento na divergência por ele mantida com Max Gluckman.

Bohannan considera que discutir o direito e as instituições jurídicas implica levar em conta os traços que caracterizariam todas as instituições, ${ }^{69}$ dentre os quais sublinha o fato de que uma instituição em ação seria marcada por certo número de atos sociais característicos (characteristic social acts). Conforme o autor, três ações típicas definiriam uma situação como jurídica. Em primeiro lugar, ocorreria um ato social quando uma norma é violada ( a breach of norm). Nesse particular, Bohannan ressalta que a norma expressa o que as pessoas devem fazer. Desse modo, a norma não é um ato social, e sim um guia para a ação social. ${ }^{70}$ Os atos podem estar de acordo ou em desacordo com as normas. Logo, violações da norma são sempre atos sociais. Em segundo lugar, está a reação ensejada pela violação da norma, que Bohannan propõe designar de "neutralização" (counteraction). Segundo ele, tais reações teriam por finalidade combater a violação das normas. Em terceiro lugar, ocorreria uma série de atividades que o autor designa de "correção" (correction) que, conforme Bohannan, significaria tanto o restabelecimento da situação anterior à violação como a redefinição do padrão normativo a ser seguido. ${ }^{71}$

which settles disputes through the exercise of that authority. Bicentric or multicentric power systems, which include the law of stateless societies and international law, are characterized by the absence of any superordinate authority" (MOORE, Sally Falk. Law as process. An anthropological approach. Hamburg: LIT, 2000 p. 217).

68 Cf. BOHANNAN, Paul. Social anthropology. New York: Holt, Rinehart and Winston, 1963. p. 283.

${ }_{69}$ A respeito, Bohannan afirma que "institutions are characterized by a social organization, a purpose, by material and ideal culture" (BOHANNAN, Paul. Social anthropology. New York: Holt, Rinehart and Winston, 1963. p. 284).

70 Segundo Bohannan, "a norm - be it law, custom, ethical precept, morals, manners, or whatever - is not a social act. It is a guide to social action" (BOHANNAN, Paul. Social anthropology. New York: Holt, Rinehart and Winston, 1963. p. 284).

71 No que concerne a essa terceira característica que define uma situação como jurídica, Bohannan afirma que 
Assim, segundo Bohannan, a "sequência dos eventos" que caracterizam uma instituição jurídica poderia ser representada pelo diagrama reproduzido a seguir:

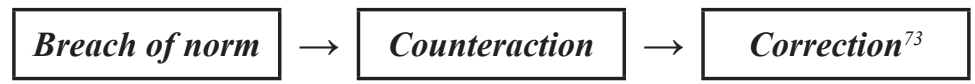

É por esse motivo que Bohannan concebe as regras jurídicas em termos de "dupla institucionalização" (double institutionalized), ou seja, como expressivas de obrigações vinculativas que foram "reinstitucionalizadas" (reinstitutionalized) no âmbito da instituição jurídica, entendida esta última como uma instância que regula conflitos e neutraliza abusos ou desvios das regras sociais. Dessa forma, a diferença entre as regras jurídicas e as demais regras sociais consistiria no fato de que as primeiras seriam detentoras de uma dupla legitimidade (double legitimacy), na medida em que existiriam como regras nas instituições sociais, mas, ao se tornarem leis, seriam reforçadas pelas instituições jurídicas. ${ }^{73}$ Trata-se de uma concepção que, apesar de criticável, ${ }^{74}$ encontra expressiva ressonância em autores da antropologia e também da sociologia. ${ }^{75}$

A civilização ocidental, segundo Bohannan, enfocaria as instituições jurídicas de um ponto de vista particular. Construiria, assim, uma folk image a partir da qual enxergaria as situações jurídicas pelo prisma de uma noção chamada de "direito", cujo conceito central seria o de norma. ${ }^{76}$ Aliás, os próprios Tiv, estudados por Bohannan

"correction is a good word to express the meaning here because it contains an ambiguity composed of two meanings [...]. Thus, correction means either a return to the status quo ante or else the establishment of a new status quo from which normal action can again proceed" (BOHANNAN, Paul. Social anthropology. New York: Holt, Rinehart and Winston, 1963. p. 285). A respeito, ver: DAVIS, Shelton H. Introdução. In: (Org.). Antropologia do direito: estudo comparativo de categorias de dívida e contrato. Tradução de Vera Maria Cândido Pereira. Rio de Janeiro: Zahar, 1973. p. 10.

72 BOHANNAN, Paul. Social anthropology. New York: Holt, Rinehart and Winston, 1963. p. 284.

73 Para excelentes análises sintéticas dessa questão, ver: ROULAND, Norbert. Anthropologie juridique. Paris: Presses Universitaires de France, 1988. p. 143; MOORE, Sally Falk. Law as process. An anthropological approach. Hamburg: LIT, 2000. p. 221.

74 Norbert Rouland lembra que, segundo Jean-Guy Belley, a tese de Bohannan teria o problema de reduzir o direito à regulação de conflitos e simplificar demasiadamente a passagem do âmbito social ao jurídico. Cf. ROULAND, Norbert. Anthropologie juridique. Paris: Presses Universitaires de France, 1988. p. 143.

75 Niklas Luhmann, por exemplo, generaliza essa concepção de Bohannan para os antropólogos em seu conjunto, na medida em que, ao referir-se à representação dos antropólogos acerca do direito, Luhmann alude à tese da "dupla institucionalização" (Zweitinstitutionalisierung) de instituições já existentes. Cf. LUHMANN, Niklas. Das Recht der Gesellschaft. Frankfurt am Main: Suhrkamp, 1993. p. 551; (Tradução inglesa: Law as a social system. Oxford: Oxford University Press, 2004. p. 465; Tradução espanhola: El derecho de la sociedad. México: Universidad Iberoamericana, 2002. p. 627).

76 Cf. BOHANNAN, Paul. Social anthropology. New York: Holt, Rinehart and Winston, 1963. p. 286. Sobre essa questão, Étienne Le Roy, ao distinguir entre direito e juridicidade, ressalta que "le droit est un avatar particulier de la juridicité, un folk law inhérent à la vision moderne de la société" (LE ROY, Étienne. Les fondements de la socialisation juridique, entre droit et juridicité. In: Cahiers d'Anthropologie du droit 2010. Pratiques citoyennes de droit. Paris: Karthala, 2011. p. 172). Le Roy ressalta, ainda, que "la définition occidentale du Droit comme ensemble de normes sanctionnées par l'État ne correspond qu'à un 
na Nigéria, exemplificariam isso, uma vez que não teriam um corpus juris passível de ser classificado como direito. ${ }^{77}$ Não cabe aqui reconstruir em termos mais detidos a concepção de Bohannan. Para os propósitos da presente análise importa notar que, mesmo no âmbito dessa abordagem antropológica geral acerca do direito, Bohannan considera inadequado utilizar a linguagem e os conceitos ocidentais para a descrição etnográfica. Segundo ele, "the language and concepts of jurisprudence being created for comparative scientific and philosophical purposes are usually inadequate to the job of ethnographic description, even as they are essential to the ultimate task of comparison" ${ }^{78}$

A perspectiva de Paul Bohannan é muito bem explicitada no artigo "Ethnography and comparison in legal anthropology", publicado no livro Law in culture and society, editado por Laura Nader. ${ }^{79}$ Em tal artigo, Bohannan ressalta que a "antropologia do direito" (legal anthropology) seria uma espécie de "microcosmo" para a análise de problemas que afetam o campo mais amplo da "antropologia social" (social anthropology). Um desses problemas seria aquele referente à relação entre a etnografia e o que se convencionou chamar de comparação. Segundo Bohannan, trata-se, fundamentalmente, do problema relativo à natureza dos dados etnográficos (sobretudo no que concerne à organização etnográfica deles) e sua reorganização em estudos comparativos. ${ }^{80}$

folk system, un type d'expérience particulier, propre à un moment de l'histoire qui ne peut ni être généralisé (tant les divergences sont profondes entre traditions juridiques) ni sans doute généralisable (le présupposé évolutionniste qui le sous-tend étant illusoire)" (LE ROY, Étienne. Pour une anthropologie de la juridicité. Cahiers d'Anthropologie du droit 2004. Anthropologie et droit - intersections et confrontations. Paris: Karthala, 2004. p. 246). Ver também: LE ROY, Étienne. Le tripode juridique. Variations anthropologiques sur un thème de flexible droit. L'Année Sociologique, Paris, n. 2, v. 57, 2007. p. 344. Para uma análise da perspectiva Étienne Le Roy, ver: VILLAS BÔAS FILHO, Orlando. Juridicidade: uma crítica à monolatria jurídica como obstáculo epistemológico. Revista da Faculdade de Direito da Universidade de São Paulo, São Paulo, v. 109, p. 281-325, jan.-dez. 2014; EBERHARD, Christoph. Para uma teoria jurídica intercultural: o desafio dialógico. Revista Direito e Democracia, Canoas, v. 3, n. 2, jul.-dez. 2002. p. 489-530.

77 Referindo-se a Bohannan, Moore ressalta que "he argues that the Tiv have rules of conduct, but that these rules are not thought of by the Tiv as a 'body of rules', as a corpus juris. Thus he says the Tiv have 'laws' but not "law"' (MOORE, Sally Falk. Law as process. An anthropological approach. Hamburg: LIT, 2000. p. 227). A respeito, ver também: NADER, Laura. The life of the law: anthropological projects. Berkeley: University of California Press, 2002. p. 26. Para uma sintética análise relativa à articulação política entre os Tiv, ver: BALANDIER, Georges. Anthropologie politique. 5. ed. Paris: Presses Universitaires de France, 2007. p. 72.

78 BOHANNAN, Paul. Social anthropology. New York: Holt, Rinehart and Winston, 1963. p. 284.

79 Cumpre notar que há uma versão em português desse importante artigo no livro intitulado Antropologia do direito: estudo comparativo de categorias de dívida e contrato, organizado por Shelton H. Davis. A tradução, entretanto, é muito precária, motivo pelo qual o texto será referenciado no original.

80 Cf. BOHANNAN, Paul. Ethnography and comparison in legal anthropology. In: NADER, Laura (Ed.). Law in culture and society. Berkeley, California: University of California Press, 1997. p. 401. 
Conforme Bohannan, ${ }^{81}$ esse problema se projetaria em quatro áreas principais: (i) a questão do uso de termos nativos no relato etnográfico (the use of native terms in reporting ethnography); (ii) a ideia de folk system e a forma pela qual a distorção inevitável das ideias nativas pode ser controlada; (iii) as "ginásticas intelectuais" (intellectual gymnastics) que têm sido denominadas comparação (às quais ele chama de chimeras of comparison); (iv) da diferença entre "teoria e cultura da etnografia" (theory and culture of ethnography) e "teoria e cultura da comparação" (theory and culture of comparison). Para tratar dessas questões, Bohannan inicia sua análise aludindo à segunda edição do livro The judicial process among the Barotse, publicado originalmente em 1955. ${ }^{82}$ Tal é, portanto, o horizonte mais diretamente visado pelo referido artigo de Bohannan, que será examinado a seguir a partir da composição quadripartida que o autor lhe imprime. ${ }^{83}$

\subsection{A questão dos termos nativos}

Ao tratar da questão relativa ao uso de termos nativos no relato etnográfico, Bohannan retoma sua discussão com Gluckmann. Para introduzir a discussão, referese a uma passagem da resenha feita por Mary Douglas acerca do livro de Gluckman, segundo a qual "c'est précisément dans cette interposition de formes de pensée étrangères que réside l'acte d'interprétation". Ora, segundo Bohannan, todo o problema residiria na interposição de formas de pensamento estrangeiro sobre as dos sistemas nativos estudados. Segundo ele, na perspectiva de Gluckman, o ato de interpretação passaria a consistir numa simples "justaposição de ideias previamente desconexas" (juxtaposition of previously unconnected ideas). ${ }^{84}$

Referindo-se a uma passagem em que Gluckman afirma a possibilidade de projetar conceitos ocidentais para a descrição não distorcida de folk concepts de outras culturas, ao menos por cortesia para com os leitores, Bohannan assevera que, numa tal

$\overline{81}$ Cf. BOHANNAN, Paul. Ethnography and comparison in legal anthropology. In: NADER, Laura (Ed.). Law in culture and society. Berkeley, California: University of California Press, 1997. p. 401.

82 Nessa segunda edição, publicada em 1967, com algumas correções, houve a adição de dois novos capítulos nos quais o autor realiza uma reavaliação de sua análise original à luz das críticas a ela dirigidas, especialmente por Bohannan (cap. IX), e uma análise das mudanças ocorridas entre os Barotse, sobretudo no que se refere à organização de suas cortes e de seu direito, entre 1947 e 1965 (cap. X). A respeito, ver: GLUCKMAN, Max. The judicial process among the Barotse of Northern Rhodesia (Zambia). 2. ed. Manchester: Manchester University Press, 1973. p. 368 e ss.

83 Cumpre ressaltar que esse artigo em que Bohannan ataca fortemente a perspectiva de Gluckman foi apresentado após a conferência Wenner-Gren de 1966. Não foi, portanto, objeto de uma resposta de Gluckman quando este apresentou seu posicionamento na referida conferência. Cf. MOORE, Sally Falk. Law as process. An anthropological approach. Hamburg: LIT, 2000. p. 139.

84 Cf. BOHANNAN, Paul. Ethnography and comparison in legal anthropology. In: NADER, Laura (Ed.). Law in culture and society. Berkeley, California: University of California Press, 1997. p. 402. 
perspectiva, o pesquisador se encontraria diante de um dilema: ou adota termos nativos e cria dificuldades para o leitor, facilitando as coisas para si, ou facilita as coisas para o leitor, não usando os termos nativos, dificultando, entretanto, as coisas para si. Diante disso, a solução pareceria estar na utilização dos termos nativos com a inserção de notas explicativas na língua do etnólogo, o que implicaria ampliar ou reduzir o sentido que as palavras têm na cultura do etnógrafo de modo a permitir que transmitam o sentido preciso da cultura observada. ${ }^{85}$

Contudo, Bohannan não concorda com essa "etnografia fácil". Segundo ele, se o analista não está preocupado com as nuances de cada cultura e com os termos explicativos de suas especificidades, então ele não é etnógrafo. Por isso, a boa etnografia seria naturalmente difícil, qualquer que seja o método utilizado. ${ }^{86}$ Segundo ele, todo etnógrafo tem o compromisso de ser rigoroso consigo, com o povo por ele estudado e com os seus colegas. É claro que ele pode e deve traduzir quando isso for possível, de modo a não tornar inviável o acesso dos demais aos dados por ele coletados, mas há situações em que o uso de palavras familiares compromete a explicação na medida em que simula a compreensão, escamoteando as distorções. Assim, o elogio feito por Edward Adamson Hoebel e Victor Ayoub à perspectiva de Gluckman seria, aos olhos de Bohannan, baseado nessa ilusão gerada pelo uso de termos familiares para explicar especificidades culturais de outros povos. ${ }^{87}$

Bohannan considera de todo inadequada a perspectiva de Gluckman segundo a qual, para fins analíticos, a ciência do direito inglesa (English jurisprudence) forneceria um vocabulário mais apropriado que a linguagem do direito tribal. ${ }^{88}$ Segundo Bohannan, a ciência do direito inglês teria desenvolvido um vocabulário para exprimir o direito inglês. ${ }^{89}$ Os Tiv, por exemplo, não teriam desenvolvido uma ciência do direito,

85 Cf. GLUCKMAN, Max. The judicial process among the Barotse of Northern Rhodesia (Zambia). 2. ed. Manchester: Manchester University Press, 1973. p. 381 (trecho encontra-se reproduzido supra, nota 45).

${ }^{86}$ Cf. BOHANNAN, Paul. Ethnography and comparison in legal anthropology. In: NADER, Laura (Ed.). Law in culture and society. Berkeley, California: University of California Press, 1997. p. 402.

87 Cf. BOHANNAN, Paul. Ethnography and comparison in legal anthropology. In: NADER, Laura (Ed.). Law in culture and society. Berkeley, California: University of California Press, 1997. p. 403-404. A respeito, ver: MOORE, Sally Falk. Certainties undone: fifty turbulent years of legal anthropology, 1949-1999, p. 99.

88 De fato, Gluckman afirma que "it seems to me that the refinements of English, and in general European, jurisprudence provide us with a more suitable vocabulary, despite of its connotations, than do the languages of tribal law" (GLUCKMAN, Max. The judicial process among the Barotse of Northern Rhodesia (Zambia). 2. ed. Manchester: Manchester University Press, 1973. p. 382). A respeito, ver: NADER, Laura. The anthropological study of law. American Anthropologist, Arlington, v. 67, n. 6, Dec. 1965. p. 11.

89 Referindo-se a Bohannan, Moore ressalta que "his argument is fundamentally that English legal terms are so inextricably bound up with the content of English law that they cannot be used effectively to describe another system" (MOORE, Sally Falk. Law as process. An anthropological approach. Hamburg: LIT, 2000. p. 140). A respeito, ver também: KROTZ, Esteban. Sociedades, conflictos, cultura y derecho desde una perspectiva antropológica. In:

(Ed.) Antropología jurídica: perspectivas socioculturales en el estudio del derecho. Rubí (Barcelona): Anthropos Editorial; México: Universidad Autónoma Metropolitana 
de modo que, ao aplicar o vocabulário próprio da ciência do direito inglês, o etnógrafo acaba fazendo pelo direito dos Tiv algo que eles próprios não teriam feito por si mesmos. Referindo-se a essa questão, Bohannan ressalta que essas duas linguagens não seriam equivalentes, de modo que a justaposição de uma à outra não implicaria apenas uma mudança de linguagem, mas uma mudança de "meio de comunicação". Por esse motivo, a perspectiva de Gluckman seria, no limite, tendencialmente etnocêntrica e expressaria um "conceito egocêntrico de comparação" (an egocentric concept of comparison). ${ }^{90}$

Aludindo à perspectiva de Hoebel, para quem o folk system dos Tiv constituiria também ele uma idealização do processo legal que na realidade ocorre entre eles, Bohannan procura ressaltar a impossibilidade epistemológica de representação daquilo que Hoebel designa de "coisa real". Para ele, a "coisa real" não seria diretamente acessível e, portanto, passível de representação, a não ser a partir de uma perspectiva grosseiramente etnocêntrica ou do que ele designa de folk system.

\subsection{Folk systems}

Bohannan ressalta que Gluckman interpretaria erroneamente sua posição, pois sua advertência em favor da análise de um folk system a partir de seus próprios termos não implicaria necessariamente a defesa de sua singularidade (uniqueness). Tendo isso como premissa, salienta que o que interessa não é discutir se um item de um determinado folk system é ou não singular (a não ser que se assuma uma perspectiva difusionista), e sim como ele se ajusta ao sistema conceitual mais amplo de quem o utiliza. Segundo ele, as comparações prematuras gerariam prejuízos à etnografia, pois obscureceriam a descrição do ajustamento dos elementos que compõem um determinado folk system. A respeito, destaca que haveria coisas muito mais importantes para se afirmar acerca dos folk systems do que a questão relativa à singularidade dos elementos que o compõem. ${ }^{91}$

Entretanto, aqui surge o problema da linguagem do relatório etnográfico, que é sujeito a grandes distorções por parte de quem o escreve e de quem o lê. Segundo Bohannan, um folk system consiste naquilo que o etnógrafo pensa e afirma e que lhe permite interagir com sucesso com as pessoas que está estudando. A esse respeito, Bohannan levanta o problema relativo a se saber se o folk system relatado corresponderia ao folk system existente. ${ }^{92}$ Rejeitando a tese proposta por Victor Ayoub, Bohannan enfatiza

- Iztapalapa, 2002. p. 26.

90 Cf. BOHANNAN, Paul. Ethnography and comparison in legal anthropology. In: NADER, Laura (Ed.). Law in culture and society. Berkeley, California: University of California Press, 1997. p. 404.

91 Cf. BOHANNAN, Paul. Ethnography and comparison in legal anthropology. In: NADER, Laura (Ed.). Law in culture and society. Berkeley, California: University of California Press, 1997. p. 405-406.

92 Cf. BOHANNAN, Paul. Ethnography and comparison in legal anthropology. In: NADER, Laura (Ed.). Law 
que essa questão consigna um falso problema, pois perguntar se há uma correspondência entre o folk system (entendido como a estruturação cognitiva da experiência marcada pelo descentramento das categorias de origem do etnógrafo) e um suposto folk system concreto ou real remeteria ao problema relativo à possibilidade de apreensão da "coisa real" (the real thing), o que, segundo ele, é impossível. ${ }^{93}$ Desse modo, criticando a tese de Ayoub, Bohannan realça que:

\begin{abstract}
Ayoub points out that the description of a folk system must be in the idiolect of the analyst, and that the key elements of that idiolect may or may not be taken over into the language in which he is writing. This is, of course, one facet of the primary difficulty of almost all ethnographic reporting that it must be done in a foreign language and hence is subject to vast distortion by the reader as well as by the writer. As a result, Ayoub is quite right in saying that we can never report the folk system. In one sense, obviously, there is no such thing - there are only the observable and discussable "facts" of communication and purposive action among the people. However, if the anthropologist can get the ideas so straight that he can discuss them in detail with informants in their own language, and if it is indeed the ethnographer instead of the informant who has made the major adjustment for purposes of communication, then I think he has something that can reasonably be called folk system. ${ }^{94}$
\end{abstract}

Essa longa citação é relevante aqui, pois permite captar não apenas o entendimento de Bohannan acerca da questão epistemológica relativa à cognição da realidade pelo saber antropológico, mas também sua concepção relativa ao que designa de folk system. Ao problematizar a perspectiva esboçada por Ayoub (em última análise essa crítica é extensível a Hoebel), Bohannan pretende enfatizar que um folk system é o que um etnógrafo pensa e diz que lhe permite interagir com sucesso com as pessoas que está estudando. Ou seja, trata-se do modelo em termos do qual o etnógrafo pode interagir com os nativos e, em virtude da natureza da comunicação, não pode ir além disso. Portanto, não tem cabimento perguntar se o folk system, tal como relatado pelo etnógrafo, corresponde à realidade, pois isso implicaria supor que esta é em si mesma cognoscível. ${ }^{95}$ A respeito, Bohannan enfatiza que questionar se ofolk system relatado corresponde efetivamente ao

in culture and society. Berkeley, California: University of California Press, 1997. p. 406.

93 Cf. BOHANNAN, Paul. Ethnography and comparison in legal anthropology. In: NADER, Laura (Ed.). Law in culture and society. Berkeley, California: University of California Press, 1997. p. 406.

94 BOHANNAN, Paul. Ethnography and comparison in legal anthropology. In: NADER, Laura (Ed.). Law in culture and society. Berkeley, California: University of California Press, 1997. p. 406.

95 Cf. BOHANNAN, Paul. Ethnography and comparison in legal anthropology. In: NADER, Laura (Ed.). Law in culture and society. Berkeley, California: University of California Press, 1997. p. 406. 
folk system em si seria o mesmo que realizar a absurda indagação relativamente a se uma determinada execução de uma sinfonia seria a sinfonia ela própria. ${ }^{96}$

Nesse particular, Bohannan rejeita a ideia de Ayoub de que haveria um "sistema concreto" (concrete system) que expressaria o que "existe realmente" (what is "really" out there).${ }^{97}$ A postulação de Ayoub seria, segundo Bohannan, sem sentido, pois não é possível conhecer o que existe a não ser nos termos da percepção que se pode ter daquilo que existe. ${ }^{98}$ Logo, o que Ayoub designa de "sistema concreto" seria inacessível. Essa questão é tratada por Bohannan como uma obviedade, por isso sua desqualificação da tese de Ayoub é completa. Segundo ele,

There is, of course, no possibility of ever arriving at a "fact" that is uncolored by that ethnographic instrument, the perceiver of the fact. The concrete system necessarily remains a mystery. [...] the concrete system is the 'reality', and we need say no more about it - indeed, we cannot say any more about it. The folk system is the ethnographer's action oriented reading of the concrete, which is sufficiently 'collective' as to allow him to interact successfully with the other people who utilize this system of symbols and culture traits. The analytical system is a scientific (whatever we may mean by that) reading of the folk system or of many folk systems. ${ }^{99}$

Importa notar aqui a distinção que Bohannan faz entre folk system e analytical system. O primeiro consiste numa espécie de estruturação da experiência a partir das categorias nativas que estão sendo analisadas. Consigna, assim, a interpretação orientada para a ação que o etnógrafo faz do concreto, a qual deve ser suficientemente "coletiva" para que o permita interagir com sucesso com as pessoas que utilizam esse sistema de símbolos e traços culturais. Por sua vez, o analytical system consiste na interpretação científica do sistema folk ou de muitos sistemas folk. Essa distinção é particularmente importante no debate travado com Gluckman, pois, conforme já mencionado, Bohannan o critica por elevar o folk system inglês ao patamar de um analytical system, para, a partir

96 Segundo Bohannan, "the question of whether or not the folk system as reported is the folk system strikes me as the same kind of question as whether some particular performance of a symphony is the symphony" (BOHANNAN, Paul. Ethnography and comparison in legal anthropology. In: NADER, Laura (Ed.). Law in culture and society. Berkeley, California: University of California Press, 1997. p. 407).

97 Cf. BOHANNAN, Paul. Ethnography and comparison in legal anthropology. In: NADER, Laura (Ed.). Law in culture and society. Berkeley, California: University of California Press, 1997. p. 407.

98 Conforme Moore, "Bohannan is passionately interested in perception, in the way a culture sets up and classifies reality into categories. [...] Bohannan says, 'The proper subject for study - indeed the only possible subject for study - is ... perception"” (MOORE, Sally Falk. Law as process. An anthropological approach. Hamburg: LIT, 2000. p. 143).

99 BOHANNAN, Paul. Ethnography and comparison in legal anthropology. In: NADER, Laura (Ed.). Law in culture and society. Berkeley, California: University of California Press, 1997. p. 407-408. 
daí, utilizá-lo para tentar organizar os dados brutos de outras sociedades dentro de suas categorias. $^{100}$

\subsection{Quimeras da comparação}

Feito o exame do conceito de folk system, Bohannan passa a criticar a maneira pela qual Gluckman realiza suas análises comparativas. Para tanto, recupera um ensaio de Franz Boas, publicado em 1896, no qual o autor discutia algumas quimeras que, segundo ele, teriam devastado, em nome do método comparativo, o campo da antropologia. ${ }^{101}$ Nesse sentido, resgatando a crítica de Boas à "doutrina da unidade psíquica da humanidade", Bohannan visa atacar a tese de Gluckman acerca dos processos decisórios por ele analisados entre os Lozi (grupo dominante do reino Barotse). Segundo Gluckman, haveria uma semelhança essencial entre os raciocínios indutivos e dedutivos de tal povo e os do Ocidente. ${ }^{102}$ A esse respeito, Sally Falk Moore enfatiza que Gluckman partia de uma premissa claramente não etnocêntrica, pois ele queria mostrar que os sistemas jurídicos africanos eram tão racionais (no sentido weberiano) como os ocidentais, decorrendo daí, inclusive, a possibilidade de poder compará-los e encontrar paralelos. ${ }^{103}$ Assim, para Gluckman, as premissas com as quais trabalhavam esses sistemas jurídicos podiam ser diferentes das do Ocidente, porém o processo de raciocínio (ou seja, a lógica articulada) seria semelhante. ${ }^{104}$

100 Bohannan procura enfatizar essa distinção ressaltando que "one perfects a folk system by arguing with informants; one perfects an analytical system by arguing with anthropologists" (BOHANNAN, Paul. Ethnography and comparison in legal anthropology. In: NADER, Laura (Ed.). Law in culture and society. Berkeley, California: University of California Press, 1997. p. 407). Acerca da distinção entre folk system e analytical system no pensamento de Bohannan, ver, por exemplo: DAVIS, Shelton H. Introdução. In: (Org.). Antropologia do direito: estudo comparativo de categorias de dívida e contrato. Tradução de Vera Maria Cândido Pereira. Rio de Janeiro: Zahar, 1973. p. 15 e 22; MOORE, Sally Falk. Law as process. An anthropological approach. Hamburg: LIT, 2000. p. 227-228; ROBERTS, Simon. Against legal pluralism. Some reflections on the contemporary enlargement of the legal domain. The Journal of Legal Pluralism, London, v. 30, n. 42, 1998. p. 103; ASSIER-ANDRIEU, Louis. Le juridique des anthropologues. Droit et Société, Paris, n. 5, p. 89-108, 1987.

101 Cf. BOAS, Franz. As limitações do método comparativo da antropologia, 1896. In: BOAS, Franz. Antropologia cultural. Textos selecionados, apresentação e tradução, Celso Castro. Rio de Janeiro: Zahar, 2004. p. 25-39.

102 Cf. GLUCKMAN, Max. The judicial process among the Barotse of Northern Rhodesia (Zambia). 2. ed. Manchester: Manchester University Press, 1973. p. 224 e ss.

103 Cf. MOORE, Sally Falk. Certainties undone: fifty turbulent years of legal anthropology, 1949-1999. The Journal of the Royal Anthropological Institute, London, v. 7, n. 1, Mar. 2001. p. 98. A respeito, ver também: NADER, Laura; MATTEI, Ugo. Plunder: when the rule of law is illegal. Oxford: Blackwell Publishing, 2008. p. $108 ; 229$ e 252-253.

104 A respeito, Gluckman enfatizava que "the logic that is present in Lozi judgments should be apparent from the judgments I quoted. I shall make this logic explicit, because it is unfortunately still necessary to demonstrate that Africans and other non-European peoples use process of inductive and deductive reasoning which are in essence similar to those of the West, even if the premises be different" (GLUCKMAN, Max. 
Bohannan, entretanto, aludindo a Durkheim, ressalta o perigo de se recorrer à dimensão psicológica na análise social e cultural. Remetendo novamente a Franz Boas, afirma que a única maneira de compreender adequadamente a história e a etnografia das culturas singulares seria enfocá-las a partir de seu ambiente, com seu componente psíquico, sua história e outras dimensões. ${ }^{105}$ Nesse contexto, aproveita para refutar o rótulo de relativista que lhe é imputado. Segundo ele, negar o "dogma da unidade psíquica da humanidade" ou a "aplicação irrestrita de um determinado conjunto de pressupostos" (a ciência do direito inglesa, no que tange à crítica endereçada a Gluckman) não implica assumir uma postura relativista. ${ }^{106}$

Feita essa refutação do rótulo de relativista que lhe é atribuído, Bohannan aborda outro grande problema da antropologia que, sob o nome de comparação, consistiria no que ele designa de "tradução às avessas" (backward translation). Segundo ele, a tradução da língua e da cultura do povo estudado para a linguagem e a cultura técnica da antropologia seria tarefa de todo etnógrafo. Contudo, o perigo surge quando, em meio a essa tarefa, o etnógrafo, em vez de iniciar sua análise a partir da cultura por ele estudada, parte de sua própria linguagem antropológica ou de seu idioma nativo procurando encontrar seus equivalentes na língua ou nas categorias do povo estudado. ${ }^{107}$ Ora, em sua opinião, Gluckman, em suas análises comparativas, realizaria a "tradução às avessas", ou seja, em vez de traduzir as ideias dos povos por ele estudados para torná-las acessíveis aos demais etnógrafos, ele simplesmente traduziria o sistema categorial e terminológico inglês para os povos estudados. ${ }^{108}$ Aliás, Bohannan chega mesmo a asseverar que Gluckman desenvolveria, em suas análises, uma combinação do pressuposto oculto da "unidade psíquica da humanidade" com a "tradução às avessas". ${ }^{109}$

The judicial process among the Barotse of Northern Rhodesia (Zambia). 2. ed. Manchester: Manchester University Press, 1973. p. 271).

105 Cf. BOHANNAN, Paul. Ethnography and comparison in legal anthropology. In: NADER, Laura (Ed.). Law in culture and society. Berkeley, California: University of California Press, 1997. p. 409.

106 A respeito, Bohannan distingue dois sentidos em que se pode falar de relativismo, admitindo para si o primeiro deles. Segundo ele, "'relativism' seems a shorthand term for a doctrine that holds that there is no absolute. In that sense, surely every social scientist must be a relativist. But relativism also sometimes means to some people 'anything goes"' (BOHANNAN, Paul. Ethnography and comparison in legal anthropology. In: NADER, Laura (Ed.). Law in culture and society. Berkeley, California: University of California Press, 1997. p. 410).

107 Cf. BOHANNAN, Paul. Ethnography and comparison in legal anthropology. In: NADER, Laura (Ed.). Law in culture and society. Berkeley, California: University of California Press, 1997. p. 410.

108 A respeito, Bohannan afirma que "it is obvious [...] that Gluckman is translating fundamentally Western ideas into Lozi instead of translating fundamentally Lozi ideas into English" (BOHANNAN, Paul. Ethnography and comparison in legal anthropology. In: NADER, Laura (Ed.). Law in culture and society. Berkeley, California: University of California Press, 1997. p. 411).

109 Cf. BOHANNAN, Paul. Ethnography and comparison in legal anthropology. In: NADER, Laura (Ed.). Law in culture and society. Berkeley, California: University of California Press, 1997. p. 411. 
Toda essa crítica desemboca na distinção que Bohannan propõe entre "comparação casual" e "comparação controlada". A comparação praticada por Gluckman seria, segundo ele, essencialmente uma "comparação casual" e, portanto, metodologicamente deficiente. ${ }^{110}$ A esse respeito, cabe notar que Bohannan subdivide a "comparação casual" em dois tipos básicos: a "etnocêntrica" e a "informação seletiva contra-ilustrativa" (selected counter-illuminative information). Do mesmo modo, subdivide a "comparação controlada", em "comparação com um padrão" (comparison with a standard) e "variáveis controladas" (controlled variables), sendo que esta última se subdividiria em comparações por "critérios deduzidos" ou por "critérios derivados etnograficamente". 111

\subsection{Cultura da etnografia e cultura da comparação}

Realizada essa distinção, Bohannan aponta dois problemas epistemológicos a serem enfrentados pela antropologia. O primeiro: como utilizar o relatório etnográfico para a compreensão da cultura que está sendo analisada? O segundo: como identificar qual o processo que possibilitaria derivar da etnografia as variáveis a serem utilizadas na comparação controlada? Para Bohannan, a chave para o primeiro problema estaria num maior cuidado com a explicitação dos pressupostos que norteiam as análises. A solução para o segundo problema estaria na criação de uma "linguagem totalmente nova e independente" (whole new independent language without national home) que o autor atribui (bizarramente) à linguagem Fortran, ou a alguma outra linguagem de computador. ${ }^{112}$

Não há o que se discutir acerca da solução proposta por Bohannan para o primeiro problema epistemológico a ser enfrentado pela antropologia. Sem dúvida

110 Cf. MOORE, Sally Falk. Law as process. An anthropological approach. Hamburg: LIT, 2000. p. 144.

$111 \mathrm{Na}$ verdade, depois de distinguir esses tipos de "comparação casual" e de "comparação controlada", Bohannan afirma que a perspectiva de Gluckman oscilaria entre o que ele designa de "comparação casual fundada em informação seletiva contra-ilustrativa" e "comparação controlada a partir de um padrão", o que a tornaria criticável tanto por postular um conjunto a priori de conceitos e categorias como por selecionar apenas casos positivos. Cf. BOHANNAN, Paul. Ethnography and comparison in legal anthropology. In: NADER, Laura (Ed.). Law in culture and society. Berkeley, California: University of California Press, 1997. p. 414. Segundo Moore, apesar de frutífera, a comparação controlada proposta por Bohannan não seria capaz de solucionar os problemas que interessam a Gluckman. Cf. MOORE, Sally Falk. Law as process. An anthropological approach. Hamburg: LIT, 2000. p. 144-145.

112 Cf. BOHANNAN, Paul. Ethnography and comparison in legal anthropology. In: NADER, Laura (Ed.). Law in culture and society. Berkeley, California: University of California Press, 1997. p. 414-415. A respeito, ver, por exemplo: MOORE, Sally Falk. Law as process. An anthropological approach. Hamburg: LIT, 2000. p. 140. Cumpre notar que Fortran consiste na abreviação de formula translation, que consiste numa linguagem de informática usada especialmente para cálculos científicos. No final da década de 60 , Bohannan parecia estar convicto de que essa linguagem se desenvolveria no campo dos estudos comparativos em antropologia. 
alguma, uma explicitação mais consequente dos pressupostos que norteiam as análises e o cuidado em não atribuir à totalidade desestruturada da etnografia o estatuto de "algum tipo de construção lógica" (some kind of logical construct) parecem de grande valia para a compreensão da cultura que constitui objeto de um dado relatório etnográfico. Contudo, a “solução" proposta por Bohannan para o segundo problema é francamente insatisfatória e, ademais, irrealista. ${ }^{113}$ Trata-se de uma proposição criticada, com razão, por Clifford Geertz que questiona a possibilidade de construção de algum "esperanto milagroso" (miraculous Esperanto) a partir do qual qualquer coisa que seja diferente, original ou estranha possa ser dita de uma maneira absolutamente neutra. Nesse sentido, Geertz ironiza a tentativa desesperada de Bohannan de encontrar na linguagem Fortran a alternativa para a análise de categorias africanas em termos das ocidentais. ${ }^{114}$

3. O debate entre Max Gluckman e Paul Bohannan para além de seus protagonistas

A importância do debate entre Max Gluckman e Paul Bohannan é inquestionável. As consequências epistemológicas de cada uma das posições antagônicas nele desenvolvidas refletem-se fortemente no debate antropológico ainda hoje. ${ }^{115}$ Tratase, portanto, de uma discussão cujo interesse não se restringe apenas às análises voltadas à história da antropologia jurídica. Os impasses que decorrem dessa discussão permeiam quaisquer pesquisas etnográficas e antropológicas preocupadas em refletir acerca de suas próprias condições epistemológicas de constituição. Decorrem daí a ampla ressonância por ela recebida e todo o cuidado de importantes autores em superar os impasses nela explicitados. Laura Nader considera que Hoebel teria conseguido compatibilizar as perspectivas de Gluckman e Bohannan a partir de um diagrama que distinguiria três níveis básicos escalonados entre si: o nível dos folk systems, o nível dos analytical systems (quando existentes) e o nível do que ele designa de comparative analytical system (a ser

113 De qualquer modo, em meio a isso, há uma questão importante que define a posição de Bohannan. Comparando sua perspectiva à de outros autores, Bohannan observa que "the comparatists, from Tylor to Gluckman, want to compare substantive material; I want, rather, to compare viewpoints or theories of substantive material." BOHANNAN, Paul. Ethnography and comparison in legal anthropology. In: NADER, Laura (Ed.). Law in culture and society. Berkeley, California: University of California Press, 1997. p. 416. A respeito, ver: MOORE, Sally Falk. Law as process. An anthropological approach. Hamburg: LIT, 2000. p. 142.

114 Cf. GEERTZ, Clifford. Local knowledge: further essays in interpretive anthropology. New York: Basic Books, 1983. p. 225. A respeito, ver também: DAVIS, Shelton H. Introdução. In: (Org.). Antropologia do direito: estudo comparativo de categorias de dívida e contrato. Tradução de Vera Maria Cândido Pereira. Rio de Janeiro: Zahar, 1973. p. 23. Nesse particular, Sally Falk Moore também critica a proposta de Hohfeld (formulada em 1923) de criar um vocabulário neutro e altamente especializado para a descrição de todas as relações jurídicas. Cf. MOORE, Sally Falk. Law as process. An anthropological approach. Hamburg: LIT, 2000. p. 142.

115 Cf. VANDERLINDEN, Jacques. Anthropologie juridique. Paris: Dalloz, 1996. p. 88. 
progressivamente desenvolvido) para lidar com todos os folk systems a partir de conceitos que podem ser provenientes de quaisquer dos níveis inferiores. ${ }^{116}$

Seja como for, o fato é que, conforme bem o nota Jacques Vanderlinden, a solução para tal controvérsia e a tentativa de equacionar os impasses dela decorrentes não estão na adoção de uma ou de outra das posições antagônicas que lhe são constitutivas. ${ }^{117}$ Segundo Norbert Rouland, cada uma dessas posições apresenta vantagens e desvantagens. A posição de Bohannan traz como vantagem uma maior precisão analítica, porém como desvantagem a possibilidade de inviabilizar as macrocomparações, levando, no limite, ao solipsismo analítico de formações culturais estanques. Por conseguinte, o que restaria de uma postura como a de Bohannan seria apenas a análise etnográfica. Por outro lado, a posição de Gluckman apresentaria a vantagem de facilitar a macrocomparação entre culturas, porém a desvantagem de introduzir elementos etnocêntricos na análise. ${ }^{118}$

Norbert Rouland também assume uma posição intermediária, inclinandose, porém, à solução sugerida por Jean Poirier. Desse modo, sustenta que existiriam categorias universais de pensamento (tais como lícito/ilícito; belo/feio; justo/injusto) e conceitos jurídicos universais (por exemplo, casamento, divórcio, autoridade parental). Contudo, por outro lado, várias categorias ocidentais, herdadas, sobretudo, do Direito Romano - como as que se expressam nas distinções entre direitos reais e pessoais, público e privado, móvel e imóvel ou patrimonial e extrapatrimonial -, seriam, em geral, intransponíveis, sem as devidas mediações, para a análise de outras culturas. De qualquer forma, enfatiza que, no plano metodológico, independentemente da posição que se tenha a

116 Segundo Laura Nader, "Intellectual agreement between Bohannan and Gluckman was arrived at by Professor Hoebel's skillful statement of the question [...]. Bohannan's position focused on the importance of the ethnographer's getting at what Tiv think about their own system; this is the Tiv analytical system. Gluckman has proved that the Barotse also have a folk analytical system. We need further a comparative analytical system competent to deal with all the folk systems. We can draw concepts from any of the lower levels to obtain the concepts for our comparative analytical system [...]. Bohannan suggested that for analytical purposes the folk system should be seen to include Tiv law as well as Tiv folk analytical system [...]. Selected parts of what is in the folk analytical systems can be taken to the comparative analytical box. It was at one time felt that the folk analysis of Western jurisprudence was sufficient in itself for the comparative box. This view is no longer considered valid; Gluckman and Bohannan agreed on this point, at least at that time" (NADER, Laura. Introduction. In: NADER, Laura (Ed.). Law in culture and society. Berkeley, California: University of California Press, 1997. p. 4-5).

117 Segundo Vanderlinden, “disons seulement que, comme souvent, la solution ne réside pas dans l'adoption de l'un ou l'autre des extrêmes en attendant que la comparaison des droits ait permis de progresser sur la voie d'un langage symbolique réduisant, au seul niveau de la notion et du concept, les particularités propres à chaque système juridique" (VANDERLINDEN, Jacques. Anthropologie juridique. Paris: Dalloz, 1996. p. 88).

118 Cf. ROULAND, Norbert. Anthropologie juridique. Paris: Presses Universitaires de France, 1988. p. 173174. Étienne Le Roy também enfatiza a premissa etnocêntrica que subjaz à perspectiva de Gluckman. Cf. LE ROY, Étienne. L'anthropologie juridique anglo-saxonne et l'héritage scientifique de Max Gluckman: un point de vue français. The Journal of Legal Pluralism and Unofficial Law, London, v. 11, n. 17, 1979. p. 53-54. 
respeito da universalidade ou da especificidade de tais categorias, é indispensável realizar um inventário cuidadoso dos termos e formulações jurídicas autóctones, uma vez que apenas a partir de um repertório bem construído que se pode, num segundo momento, decidir se tais categorias possuem ou não equivalência em nosso sistema jurídico de origem. $^{119}$

Tendo por horizonte essas questões que, em última instância, remontam ao debate entre Gluckman e Bohannan, Norbert Rouland sugere algumas diretivas que, em seu entendimento, seriam fundamentais para a realização de comparações no âmbito da análise antropológica do direito. Ao afirmar que considera as macrocomparações possíveis, o autor procura estabelecer os princípios metodológicos que devem reger a sua realização. Para tanto, analiticamente, distingue entre: a) o âmbito da comparação; b) o objeto da comparação; c) a natureza da comparação.

No tocante à primeira dimensão, Rouland, apoiando-se em Lévi-Strauss, ressalta que a comparação pode ser feita a partir de uma abordagem geográfica, histórica ou temática. Ora, segundo ele, seja qual for a base em que se funde a comparação, esta sempre demanda um modelo que defina claramente os elementos e os sistemas a serem comparados, os eixos de comparação e o tipo de formulação que orienta seus resultados. Aliás, no que concerne à última fase da análise comparativa, Rouland salienta que esta se refere à formulação de leis gerais, baseadas nas comparações transculturais. ${ }^{120}$ No que tange ao objeto da comparação, referindo-se a Franz Benda-Beckmann, alude a três dimensões de variabilidade às quais toda análise comparativa transcultural deve fazer menção. A primeira referir-se-ia à extensão do campo reconhecido ao direito, uma vez que há graus variáveis de institucionalização da regulação jurídica conforme se esteja numa sociedade ou noutra. A segunda remeteria ao grau de limitação que o direito, sejam quais forem as dimensões assumidas por seu campo de ação, exerce na autonomia dos membros da sociedade. A terceira consistiria na intensidade das ligações entre o direito geral e o concreto. ${ }^{121}$ Por fim, no que tange à natureza da comparação, Rouland indica dois princípios que, em sua avaliação, seriam fundamentais: a) devem-se comparar não os elementos em si, mas os sistemas aos quais eles pertencem, uma vez que são tais sistemas que dão sentido aos elementos; b) deve-se distinguir a comparação entre sistemas culturais que têm a mesma lógica e sistemas culturais que têm lógicas distintas. No primeiro caso, seria possível realizar apenas uma simples confrontação das respostas dadas pelos sistemas a questões idênticas. No segundo caso seria preciso realizar uma

119 Cf. ROULAND, Norbert. Anthropologie juridique. Paris: Presses Universitaires de France, 1988. p. 174.

120 Cf. ROULAND, Norbert. Anthropologie juridique. Paris: Presses Universitaires de France, 1988. p. 174175 .

121 Cf. ROULAND, Norbert. Anthropologie juridique. Paris: Presses Universitaires de France, 1988. p. 175. 
mediação que tem por base a procura de "equivalentes homeomorfos" entre as culturas comparadas. ${ }^{122}$

Toda essa reflexão de método proposta por Norbert Rouland se coloca na esteira da discussão de Gluckman e Bohannan a respeito da comparação. De um lado, identifica-se nela a intenção de Gluckman de realizar uma ampla análise comparativa que escape a um solipsismo etnográfico incapaz de transcender os particularismos inerentes a formações culturais distintas. Por outro, observa-se nessa proposta de Rouland a assimilação do teor das críticas de Bohannan acerca das por ele designadas "quimeras da comparação" e de sua proposta de uma "comparação controlada", nos termos expostos supra. Aliás, a proposta de Norbert Rouland parece justamente esboçar uma conciliação entre as duas perspectivas, corroborando, assim, a assertiva de Vanderlinden de que a solução do impasse existente entre os autores não estaria na adoção de uma ou de outra das posições que se polarizam no debate havido entre eles. ${ }^{123}$ Aliás, no que concerne a essa questão, vários autores, como John Comaroff e Simon Roberts, consideram que o debate entre Gluckman e Bohannan se fundaria num falso problema. ${ }^{124}$ Baseando-se em Frank Cancian, Laura Nader ressalta que o desacordo entre os dois autores não estaria no nível descritivo, mas no analítico. ${ }^{125}$ Segundo Sally Falk Moore, o desacordo entre Gluckman e Bohannan seria limitado, uma vez que ambos estariam claramente conscientes das dificuldades inerentes à descrição e à tradução das características de sistemas jurídicos de outras culturas, assim como do fato de que tais dificuldades se multiplicam quando se

122 A respeito, Rouland dá o exemplo dos direitos humanos. Segundo ele, tratando-se de sociedades com lógicas diferentes, não se deve tentar procurar a aplicação de um suposto conceito universal de direitos humanos, mas sim tentar procurar nas outras culturas, o que poderia servir como equivalente a esse conceito ocidental para assegurar a dignidade humana. Cf. ROULAND, Norbert. Anthropologie juridique. Paris: Presses Universitaires de France, 1988. p. 176. A respeito, ver, por exemplo: ADONON, Akuavi; PLANÇON, Caroline; EBERHARD, Christoph. Les cultures juridiques. In: RUDE-ANTOINE, Edwige; CHRÉTIENVERNICOS, Geneviève (Coord.). Anthropologies et droits: état des savoirs et orientations contemporaines. Paris: Dalloz, 2009. p. 205-243; EBERHARD, Christoph. Le droit au miroir des cultures. Pour une autre mondialisation. 2.ed. revue et augmentée. Paris: LGDJ, 2010. p. 110 e ss; EBERHARD, Christoph. Les droits de l'homme face à la complexité: une approche anthropologique et dynamique. Droit et Société, Paris, n. 51/52, p. 455-486, 2002. A respeito, ver: NICOLAU, Gilda; PIGNARRE, Geneviève; LAFARGUE, Régis. Ethnologie juridique: autour de trois exercices. Paris: Dalloz, 2007. p. 1, nota 3 e p. 7.

123 Conforme enfatiza Norbert Rouland, "il n'y a pas de valeurs ou de normes juridiques transcendant la pluralité des cultures, car une valeur n'a de signification que par rapport au système culturel dans lequel elle opere, mais em revanche une comparaison transculturelle entre les valeurs est possible" (ROULAND, Norbert. Anthropologie juridique. Paris: Presses Universitaires de France, 1988. p. 176). Cf. VANDERLINDEN, Jacques. Anthropologie juridique. Paris: Dalloz, 1996. p. 88.

124 Cf. COMAROFF, John L.; ROBERTS, Simon. Rules and processes: the cultural logic of dispute in an African context. Chicago: University of Chicago Press, 1986. p. 252.

125 Cf. NADER, Laura. Introduction. In: NADER, Laura (Ed.). Law in culture and society. Berkeley, California: University of California Press, 1997. p. 5. 
atinge o nível da análise comparativa. A divergência restringir-se-ia, portanto, à solução dada por eles a essas dificuldades. ${ }^{126}$

Seja qual for a extensão que se atribua à divergência existente entre Gluckman e Bohannan, o fato é que ela toca em questões epistemológicas fundamentais que serão, inclusive, objeto de importantes análises posteriores. No que concerne a Bohannan, Simon Roberts salienta que a distinção entre descrição e análise, que sustenta a clivagem entre folk system e analytical system, tornou-se rapidamente controvertida e considerada fundada no senso comum. A esse respeito, alude à ênfase dada por Geertz à dimensão interpretativa da escrita etnográfica e também à sua problematização da dimensão comparativa do projeto antropológico. Segundo Roberts, Geertz também sublinha a importância do sentido num nível que não é devidamente apreendido na oposição entre folk system e analytical system, pois ressalta o sentido subjacente (underlying meaning) de padrões e regularidades não percebidos pelos atores, colocando em questão a proveniência do arcabouço teórico mobilizado na análise etnográfica. ${ }^{127}$ Por outro lado, Geertz também toma uma posição de distanciamento em relação à perspectiva de Gluckman. ${ }^{128}$ Aludindo ao livro Local Knowledge, Sally Falk Moore observa que Geertz considera o direito "uma espécie de imaginação social". Assim sendo, a análise comparativa - ao tomá-lo enquanto tal - deve realçar as diferenças culturais, e não os universais de Gluckman. ${ }^{129}$ Aliás, Moore destaca que a ênfase de Bohannan e de Geertz na importância da diferença cultural, inclusive, teria ressonância nos debates atuais do multiculturalismo e em teorias do reconhecimento, tais como a de Charles Taylor. ${ }^{130}$

A discussão entre Gluckman e Bohannan também reverbera, por exemplo, na teoria do multijuridismo de Étienne Le Roy. A esse respeito, é possível apontar paralelos entre a posição de Bohannan e a de Le Roy. Conforme ressaltado, ao explicitar suas reservas em relação à perspectiva de Gluckman, Bohannan critica intensamente a conversão de um dado folk system (aquele de onde provém o antropólogo) ao patamar

126 Cf. MOORE, Sally Falk. Law as process. An anthropological approach. Hamburg: LIT, 2000. p. 140-141.

127 Cf. GEERTZ, Clifford. The interpretation of cultures. New York: Basic Books, 1973. p. 9 e 25. A respeito, ver: ROBERTS, Simon. Against legal pluralism. Some reflections on the contemporary enlargement of the legal domain. The Journal of Legal Pluralism, London, v. 30, n. 42, p. 95-106, 1998.

128 Cf. MOORE, Sally Falk. Certainties undone: fifty turbulent years of legal anthropology, 1949-1999. The Journal of the Royal Anthropological Institute, London, v. 7, n. 1, Mar. 2001. p. 99.

129 Cf. MOORE, Sally Falk. Certainties undone: fifty turbulent years of legal anthropology, 1949-1999. The Journal of the Royal Anthropological Institute, London, v. 7, n. 1, Mar. 2001. p. 99.

130 Cf. MOORE, Sally Falk. Certainties undone: fifty turbulent years of legal anthropology, 1949-1999. The Journal of the Royal Anthropological Institute, London, v. 7, n. 1, Mar. 2001. p. 99. Aliás, esse é um dos motivos pelos quais a perspectiva de Geertz se faz importante para análises como a de Luís Roberto Cardoso de Oliveira. Cf. OLIVEIRA, Luís Roberto Cardoso de. Direito legal e insulto moral: dilemas da cidadania no Brasil, Quebec e EUA. Rio de Janeiro: Relume Dumará, 2002; OLIVEIRA, Luís Roberto Cardoso de. A dimensão simbólica dos direitos e a análise de conflitos. Revista de Antropologia da USP, São Paulo, v. 53, n. 2, jul.-dez. 2010. p. 465-466. 
de um analytical system. ${ }^{131}$ Algo semelhante se observa na proposta de Étienne Le Roy, uma vez que, segundo ele, o termo "Direito" representaria um folk system que, como conjunto de normas sancionadas pelo Estado, expressaria apenas uma forma particular de experiência, própria de um contexto histórico e social - o Ocidente moderno - que, por esse motivo, não pode ser generalizada à guisa de universal. ${ }^{132}$ É nesse sentido que Le Roy sustenta a distinção entre direito e juridicidade a partir da qual enfoca o direito como um avatar da juridicidade que o transcende e engloba. ${ }^{133}$ Trata-se, assim, de uma perspectiva que, ao propor um descentramento da concepção ocidental de direito, concebe a juridicidade como um "domínio comum de regulação", no qual a experiência ocidental figura apenas como um folk system, entre outros. ${ }^{134}$

131 Segundo Bohannan, "the anthropologist's chief danger is that he will change one of the folk systems of his own society into an analytical system, and try to give wider application than its merit and usefulness allow" (BOHANNAN, Paul. Justice and judgment among the Tiv. Oxford: Oxford University Press, 1957, p. 5 apud ROBERTS, Simon. Against legal pluralism. Some reflections on the contemporary enlargement of the legal domain. The Journal of Legal Pluralism, London, v. 30, n. 42, 1998. p. 103).

132 A respeito, Le Roy ressalta que "la définition occidentale du Droit comme ensemble de normes sanctionnées par l'État ne correspond qu'à un folk system, un type d'expérience particulier, propre à un moment de 1'histoire qui ne peut ni être généralisé (tant les divergences sont profondes entre traditions juridiques) ni sans doute généralisable (le présupposé évolutionniste qui le sous-tend étant illusoire)" (LE ROY, Étienne. Pour une anthropologie de la juridicité. Cahiers d'Anthropologie du droit 2004. Anthropologie et droit intersections et confrontations. Paris: Karthala, 2004. p. 246).

133 A respeito, ver, por exemplo: LE ROY, Étienne. Autonomie du droit, hétéronomie de la juridicité. In: SACCO, Rodolfo (Ed.). Le nuove ambizioni del sapere del giurista: antropologia giuridica e traduttologia giuridica. Roma: Accademia Nazionale dei Lincei, 2009. p. 99-133; LE ROY, Étienne. La terre de l'autre. Une anthropologie des régimes d'appropriation foncière. Paris: LGDJ, 2011. p. 26-27; LE ROY, Étienne. Le jeu des lois. Une anthropologie "dynamique” du Droit. Paris: LGDJ, 1999. p. 187 e ss.; LE ROY, Étienne. Le tripode juridique. Variations anthropologiques sur un thème de flexible droit. L'Année Sociologique, Paris, n. 2, v. 57, 2007. p. 343 e ss.; LE ROY, Étienne. Les appropriations de terres à grande échelle et les politiques foncières au regard de la mondialisation d'un droit en crise. Droit et Société, Paris, n. 89, 2015. p. 205; LE ROY, Étienne. Les fondements de la socialisation juridique, entre droit et juridicité. In: Cahiers d'anthropologie du droit 2010. Pratiques citoyennes de droit. Paris: Karthala, 2011. p. 172; LE ROY, Étienne. Place de la juridicité dans la médiation. Jurisprudence - Revue Critique, Chambéry, n. 4 (La médiation. Entre renouvellement de l'offre de justice et droit), 2013. p. 203-206; LE ROY, Étienne. Pour une anthropologie de la juridicité. Cahiers d'Anthropologie du droit 2004. Anthropologie et droit - intersections et confrontations. Paris: Karthala, 2004. p. 246. Para uma análise da juridicidade na obra de Étienne Le Roy, ver: VILLAS BÔAS FILHO, Orlando. Juridicidade: uma crítica à monolatria jurídica como obstáculo epistemológico. Revista da Faculdade de Direito da Universidade de São Paulo, São Paulo, v. 109, p. 281325, jan.-dez. 2014.

134 A respeito, Étienne Le Roy ressalta que "la comparaison des modes de régulation convoqués dans diverses expériences juridiques, en Europe, en Afrique ou en Amérique du Nord m'avait conduit à substituer la notion de fondement à celle de source puis à proposer trois fondements tant du droit que de la juridicité puisque, pour moi, [...] le droit est un avatar particulier de la juridicité, un folk law inhérent à la vision moderne de la société" (LE ROY, Étienne. Les fondements de la socialisation juridique, entre droit et juridicité. In: Cahiers d'anthropologie du droit 2010. Pratiques citoyennes de droit. Paris: Karthala, 2011. p. 172). Acerca do interesse teórico pelo folk law, pelo costume, pelo espírito do povo etc., ver: ARNAUD, André-Jean; FARIÑAS DULCE, María José. Introduction à l'analyse sociologique des systèmes juridiques. Bruxelles: Bruylant, 1998. p. 211. 
Finalmente, numa estreita afinidade com a perspectiva de Étienne Le Roy, autores como Robert Vachon e Christoph Eberhard, baseando-se em Raimon Panikkar, criticam o "monismo unitarista" e "totalitarismo do logos" na compreensão do fenômeno jurídico e sublinham a diversidade de "culturas jurídicas" e as diferenças radicais que lhes são constitutivas. ${ }^{135}$ Segundo os autores, diante das diferenças substanciais existentes entre tais culturas (que, por esse motivo, são por eles designadas de "homeomorfas"), seria necessário desenvolver uma abordagem intercultural e diatópica, em meio à qual ocorreria um deslocamento do logos para o mythos, uma vez que as culturas jurídicas não seriam simples objetos de conhecimento, mas realidades existenciais. ${ }^{136}$ Não cabe aqui adentrar na complexidade de tal análise. O que importa notar é que, em meio a ela, exclui-se a possibilidade de utilização dos instrumentos conceituais ocidentais para a análise de outras culturas jurídicas, o que constitui inequívoca incompatibilidade com uma perspectiva como a de Gluckman e uma proximidade, ainda que a partir de outras bases, com a de Bohannan. ${ }^{137}$

4. À guisa de conclusão (ou não): seria possível lidar com as quimeras da comparação?

Ao longo do presente artigo, procurou-se sublinhar a importância da discussão entre Max Gluckman e Paul Bohannan, sobretudo no que concerne às questões epistemológicas que dela decorrem. Assim, ressaltou-se que os autores divergem acerca de várias questões fundamentais relativas à análise antropológica do direito, em especial no que se refere a como proceder a comparação. ${ }^{138}$ Seja qual for o grau de pertinência

135 Cf. VACHON, Robert. L'Etude du pluralisme juridique: une approche diatopique et dialogale. The Journal of Legal Pluralism and Unofficial Law, London, v. 22, n. 29, January 1990. p. 164-172; EBERHARD, Christoph. Le droit au miroir des cultures. Pour une autre mondialisation. 2.ed. revue et augmentée. Paris: LGDJ, 2010. p. 37-39; EBERHARD, Christoph. Para uma teoria jurídica intercultural: o desafio dialógico. Revista Direito e Democracia, Canoas, v. 3, n. 2, jul.-dez. 2002. p. 506-510.

136 A respeito, Vachon ressalta que "on peut regarder ces cultures juridiques comme de simples objets de connaissance, des faits historiques, quantifiables, objectifiables, analysables, conceptualisables, et même intelligibles (logos comprend tout cela!). Mais elles sont beaucoup plus que cela: ce sont des réalités existentielles, personnelles (pas seulement subjectives), sacrées, mythiques. [...] Elles ne sont pas seulement de l'ordre du logos mais de l'ordre du mythos c'est-à-dire de l'ordre des différences ultimes" (VACHON, Robert. L'Etude du pluralisme juridique: une approche diatopique et dialogale. The Journal of Legal Pluralism and Unofficial Law, London, v. 22, n. 29, January 1990. p. 169).

137 A respeito, em clara consonância com Robert Vachon e Raimon Panikkar, Le Roy ressalta que "les lieux des diverses visions du monde ne peuvent être réconciliés par le recours aux outils de compréhension d'une seule culture ou tradition" (LE ROY, Étienne. Juristique et anthropologie: Un pari sur l'avenir. The Journal of Legal Pluralism and Unofficial Law, London, v. 22, n. 29, 1990. p. 11). Robert Vachon também afirma que "on ne saurait comprendre adéquatement une culture juridique homologue au moyen des seuls outils conceptuels de la seule culture juridique occidentale [...]" (VACHON, Robert. L'Etude du pluralisme juridique: une approche diatopique et dialogale. The Journal of Legal Pluralism and Unofficial Law, London, v. 22, n. 29, January 1990. p. 169).

138 Trata-se de uma questão que é clássico objeto da discussão antropológica. Para um tratamento da questão 
que se atribua a cada uma das posições envolvidas no debate, o fato é que as reservas de Bohannan em relação à perspectiva de Gluckman explicitam problemas epistemológicos espinhosos que perpassam a antropologia. Nesse particular, procurou-se sublinhar o quanto tais problemas, direta ou indiretamente, ainda se refletem na antropologia jurídica hodierna. Assim, a alusão a teóricos de distintas procedências e concepções teóricas díspares, tais como Norbert Rouland, Clifford Geertz, Simon Roberts, Sally Falk Moore, Étienne Le Roy, Robert Vachon e Christoph Eberhard, permite que se tenha em conta o quanto a polêmica entre Gluckman e Bohannan ainda se faz presente e revela impasses ainda não resolvidos pelas abordagens antropológicas acerca da regulação jurídica.

Paul Bohannan criticava vivamente certas formas de análises comparativas que, em sua perspectiva, assumiriam um viés etnocêntrico e distorceriam as formas de regulação qualificáveis como jurídicas em outras culturas, impedindo assim, sua adequada compreensão. Sua preocupação consistia em evitar o que ele designava de "quimeras da comparação" que, segundo ele, caracterizariam a perspectiva de Gluckman. Assim, a proposta de uma "comparação controlada", tal como sustentada por Bohannan, explicita as dificuldades do modo pelo qual, classicamente, a comparação é realizada. Entretanto, não resolve os problemas que são inerentes à análise comparativa. Conforme ressalta Sally Falk Moore, várias questões intrincadas também emergem da posição de Bohannan, o que seria indicativo da complexidade dos aspectos epistemológicos envolvidos na discussão por ele mantida com Gluckman. ${ }^{139}$ A consideração de tais dificuldades talvez habilitasse Gluckman a retorquir à acusação de Bohannan acerca do caráter quimérico de sua comparação. Poderia ele, recorrendo a Baudelaire, replicar "chacun sa chimère"!

São Paulo, 30 de abril de 2015.

a partir de um ascendente intelectual comum a Gluckman e Bohannan, ver: RADCLIFFE-BROWN, Alfred Reginald. The comparative method in social anthropology. In: KUPER, Adam (Ed.). The social anthropology of Radcliffe-Brown. London: Routledge \& Kegan Paul, 1977. p. 53-68. A respeito, conforme lembra Guillermo de la Peña, Max Gluckman e Paul Bohannan realizaram seus doutorados em Oxford sob a orientação de E. E. Evans-Pritchard, sucessor de Radcliffe-Brown em tal instituição. Cf. PEÑA, Guillermo de la. Costumbre, ley y procesos judiciales en la antropología clásica: apuntes introductorios. In: KROTZ, Esteban. (Ed.) Antropología jurídica: perspectivas socioculturales en el estudio del derecho. Rubí (Barcelona): Anthropos Editorial; México: Universidad Autónoma Metropolitana - Iztapalapa, 2002. p. 64.

139 Referindo-se às dificuldades que também emergem da preocupação terminológica de Bohannan, Sally Falk Moore afirma, entre outras coisas, que "a fundamental question is whether certain words, per se, may indeed be taken to represent the basic categories of people's thought. Is the semantic content of terms the best indication of fundamental classification? Are there not many mental ways of classifying ideas, only some of which are represented in the meanings of particular single words? Several words may be associated, for example. Further, one may be disposed to ask how the anthropologist chooses which words to expand on and which to disregard. [...] Another puzzling thing about the terminological approach is how, within it, one is to cope with those aspects of structure and order inherent in an indigenous system for which there may be no terms" (MOORE, Sally Falk. Law as process. An anthropological approach. Hamburg: LIT, 2000. p. 228). 


\section{Referências}

ADONON, Akuavi; PLANÇON, Caroline; EBERHARD, Christoph. Les cultures juridiques. In: RUDE-ANTOINE, Edwige; CHRÉTIEN-VERNICOS, Geneviève (Coord.). Anthropologies et droits: état des savoirs et orientations contemporaines. Paris: Dalloz, 2009. p. 205-243.

ARNAUD, André-Jean; FARIÑAS DULCE, María José. Introduction à l'analyse sociologique des systèmes juridiques. Bruxelles: Bruylant, 1998.

ASSIER-ANDRIEU, Louis. O direito nas sociedades humanas. Tradução de Maria Ermantina Galvão. São Paulo: Martins Fontes, 2000. . Le juridique des anthropologues. Droit et Société, Paris, n. 5, p. 89-108, 1987.

BALANDIER, Georges. Anthropologie politique. 5. ed. Paris: Presses Universitaires de France, 2007.

BOAS, Franz. As limitações do método comparativo da antropologia, 1896. In: BOAS, Franz. Antropologia cultural. Textos selecionados, apresentação e tradução, Celso Castro. Rio de Janeiro: Zahar, 2004. p. 25-39.

BOHANNAN, Paul. A categoria injô na sociedade Tiv. In: DAVIS, Shelton H. (Org.). Antropologia do direito: estudo comparativo de categorias de dívida e contrato. Tradução de Vera Maria Cândido Pereira. Rio de Janeiro: Zahar, 1973. p. 57-69.

. Ethnography and comparison in legal anthropology. In: NADER, Laura (Ed.). Law in culture and society. Berkeley, California: University of California Press, 1997. p. 401-418.

. Social anthropology. New York: Holt, Rinehart and Winston, 1963.

BOURDIEU, Pierre; CHAMBOREDON, Jean-Claude; PASSERON, Jean-Claude. Le métier de sociologue. 5. ed. Berlin: Mouton de Gruyter, 2005.

CLASTRES, Pierre. Arqueologia da violência: pesquisas de antropologia política. Tradução de Paulo Neves. São Paulo: Cosac \& Naify, 2004.

. La société contre l'État. Recherches d'anthropologie politique. Paris: Les Éditions de Minuit, 2011.

COMAROFF, John L.; ROBERTS, Simon. Rules and processes: the cultural logic of dispute in an African context. Chicago: University of Chicago Press, 1986.

DAVIS, Shelton H. Introdução. In: (Org.). Antropologia do direito: estudo comparativo de categorias de dívida e contrato. Tradução de Vera Maria Cândido Pereira. Rio de Janeiro: Zahar, 1973. p. 9-24.

. Victims of the miracle: development and the Indians of Brazil. New York: Cambridge University Press, 1977. 
EBERHARD, Christoph. Le droit au miroir des cultures. Pour une autre mondialisation. 2.ed. revue et augmentée. Paris: LGDJ, 2010.

. Les droits de l'homme face à la complexité: une approche anthropologique et dynamique. Droit et Société, Paris, n. 51/52, p. 455-486, 2002.

. Para uma teoria jurídica intercultural: o desafio dialógico. Revista Direito e Democracia, Canoas, v. 3, n. 2, p. 489-530, jul.-dez. 2002.

GEERTZ, Clifford. The interpretation of cultures. New York: Basic Books, 1973.

. Local knowledge: further essays in interpretive anthropology. New York: Basic Books, 1983.

GLUCKMAN, Max. The judicial process among the Barotse of Northern Rhodesia (Zambia). 2. ed. Manchester: Manchester University Press, 1973.

Obrigação e dívida. In: DAVIS, Shelton H. (Org.). Antropologia do direito: estudo comparativo de categorias de dívida e contrato. Tradução de Vera Maria Cândido Pereira. Rio de Janeiro: Zahar, 1973. p. 25-56.

HART, Herbert L. A. The concept of law. 2. ed. Oxford: Clarendon Press, 1994.

HEMMING, John. Die if you must. Brazilian Indians in the Twentieth Century. London: Macmillan, 2003.

HOEBEL, Edward Adamson. The law of primitive man: a study in comparative legal dynamics. Cambridge, Massachusetts: Harvard University Press, 2006.

JOURDAIN, Anne; NAULIN, Sidonie. La théorie de Pierre Bourdieu et ses usages sociologiques. Paris: Armand Colin, 2011.

KROTZ, Esteban. Sociedades, conflictos, cultura y derecho desde una perspectiva antropológica. In: __ (Ed.). Antropología jurídica: perspectivas socioculturales en el estudio del derecho. Rubí (Barcelona): Anthropos Editorial; México: Universidad Autónoma Metropolitana - Iztapalapa, 2002. p. 13-49.

LE ROY, Étienne. Les appropriations de terres à grande échelle et les politiques foncières au regard de la mondialisation d'un droit en crise. Droit et Société, Paris, n. 89, p. 193-206, 2015.

Autonomie du droit, hétéronomie de la juridicité. In: SACCO, Rodolfo (Ed.). Le nuove ambizioni del sapere del giurista: antropologia giuridica e traduttologia giuridica. Roma: Accademia Nazionale dei Lincei, 2009. p. 99-133.

Les fondements de la socialisation juridique, entre droit et juridicité. In: Cahiers d'anthropologie du droit 2010. Pratiques citoyennes de droit. Paris: Karthala, 2011. p. 169-192. 
LE ROY, Étienne. J. L. Comaroff and S. Roberts. Rules and processes. The cultural logic of dispute in an African context. Chicago and London, University of Chicago Press, 1981 - Book Review. The Journal of Legal Pluralism and Unofficial Law, London, v. 15, n. 21, p. 155-166, 1983.

. Le jeu des lois. Une anthropologie "dynamique” du Droit. Paris: LGDJ, 1999.

. Juristique et anthropologie: Un pari sur l'avenir. The Journal of Legal Pluralism and Unofficial Law, London, v. 22, n. 29, p. 5-21, 1990.

. L'anthropologie juridique anglo-saxonne et l'héritage scientifique de Max Gluckman: un point de vue français. The Journal of Legal Pluralism and Unofficial Law, London, v. 11, n. 17, p. 53-70, 1979.

. Place de la juridicité dans la médiation. Jurisprudence - Revue Critique, Chambéry, n. 4 (La médiation. Entre renouvellement de l'offre de justice et droit), p. 193-208, 2013.

- Pour une anthropologie de la juridicité. Cahiers d'Anthropologie du droit 2004. Anthropologie et droit - intersections et confrontations. Paris: Karthala, 2004. p. 241-247.

. La terre de l'autre. Une anthropologie des régimes d'appropriation foncière. Paris: LGDJ, 2011.

. Le tripode juridique. Variations anthropologiques sur un thème de flexible droit. L'Année Sociologique, Paris, n. 2, v. 57, p. 341-351, 2007.

LEBARON, Frédéric. Le métier de sociologue. Préalables épistémologiques. In: LEBARON, Frédéric; MAUGER, Gérard (Dir.). Lectures de Bourdieu. Paris: Ellipses, 2012. p. 111-121.

LÉVI-STRAUSS, Claude. Race et histoire. Paris: Denoël, 1987.

LIMA, Roberto Kant de. Por uma antropologia do direito, no Brasil. In: Ensaios de antropologia e de direito: acesso à justiça e processos institucionais de administração de conflitos e produção da verdade em uma perspectiva comparada. Rio de Janeiro: Lumen Juris, 2008. p. 1-38.

; VARELLA, Alex. Saber jurídico e direito à diferença no Brasil: questões de teoria e método em uma perspectiva comparativa. In: LIMA, Roberto Kant de. Ensaios de antropologia e de direito: acesso à justiça e processos institucionais de administração de conflitos e produção da verdade em uma perspectiva comparada. Rio de Janeiro: Lumen Juris, 2008. p. 89-126.

LOSANO, Mario G. Os grandes sistemas jurídicos: introdução aos sistemas jurídicos europeus e extra-europeus. Tradução de Marcela Varejão. São Paulo: Martins Fontes, 2007.

LUHMANN, Niklas. Das Recht der Gesellschaft. Frankfurt am Main: Suhrkamp, 1993. (Tradução inglesa: Law as a social system. Oxford: Oxford University Press, 2004; Tradução espanhola: El derecho de la sociedad. México: Universidad Iberoamericana, 2002).

MAINE, Henry James Sumner. Ancient law, its connection with the early history of society, and its relation to modern ideas. Tucson, Arizona: The University of Arizona Press, 1986. 
MAINE, Henry James Sumner. Lectures on the early history of institutions. 6. ed. London: John Murray, 1898.

MALINOWSKI, Bronislaw. Crime and custom in savage society. 7. ed. London: Routledge \& Kegan Paul, 1961.

MOORE, Sally Falk. Certainties undone: fifty turbulent years of legal anthropology, 1949-1999. The Journal of the Royal Anthropological Institute, London, v. 7, n. 1, p. 95-116, Mar. 2001.

. Law and anthropology: a reader. Malden/USA: Blackwell, 2005.

. Law as process. An anthropological approach. Hamburg: LIT, 2000.

NADER, Laura. The anthropological study of law. American Anthropologist, Arlington, v. 67, n. 6, p. 3-32, Dec. 1965.

. Introduction. In: NADER, Laura (Ed.). Law in culture and society. Berkeley, California: University of California Press, 1997. p. 1-10.

. The life of the law: anthropological projects. Berkeley: University of California Press, 2002.

; MATTEI, Ugo. Plunder: when the rule of law is illegal. Oxford: Blackwell Publishing, 2008.

NICOLAU, Gilda; PIGNARRE, Geneviève; LAFARGUE, Régis. Ethnologie juridique: autour de trois exercices. Paris: Dalloz, 2007.

OLIVEIRA, Luís Roberto Cardoso de. A dimensão simbólica dos direitos e a análise de conflitos. Revista de Antropologia da USP, São Paulo, v. 53, n. 2, p. 451-473, jul.-dez. 2010.

. Direito legal e insulto moral: dilemas da cidadania no Brasil, Quebec e EUA. Rio de Janeiro: Relume Dumará, 2002.

. Moral e ética. In: SOUZA LIMA, Antonio Carlos de (Coord.). Antropologia \& Direito: temas antropológicos para estudos jurídicos. Brasília/Rio de Janeiro/Blumenau: Associação Brasileira de Antropologia/Laced/Nova Letra, 2012. p. 94-102.

PEÑA, Guillermo de la. Costumbre, ley y procesos judiciales en la antropología clásica: apuntes introductorios. In: KROTZ, Esteban. (Ed.) Antropología jurídica: perspectivas socioculturales en el estudio del derecho. Rubí (Barcelona): Anthropos Editorial; México: Universidad Autónoma Metropolitana - Iztapalapa, 2002. p. 51-68.

RADCLIFFE-BROWN, Alfred Reginald. The comparative method in social anthropology. In: KUPER, Adam (Ed.). The social anthropology of Radcliffe-Brown. London: Routledge \& Kegan Paul, 1977. p. 53-68.

. Structure and function in primitive society: essays and addresses. London: Cohen \& West, 1952. 
ROBERTS, Simon. Against legal pluralism. Some reflections on the contemporary enlargement of the legal domain. The Journal of Legal Pluralism, London, v. 30, n. 42, p. 95-106, 1998.

ROULAND, Norbert. Anthropologie juridique. Paris: Presses Universitaires de France, 1988.

.L'anthropologie juridique. 2. ed. Paris: Presses Universitaires de France, 1995. (Que Saisje?)

. Nos confins do direito: antropologia jurídica da modernidade. Tradução de Maria Ermantina de Almeida Prado Galvão. São Paulo: Martins Fontes, 2003.

SACCO, Rodolfo. Antropologia jurídica: contribuição para uma macro-história do direito. Tradução de Carlo Alberto Dastoli. São Paulo: Martins Fontes, 2013.

SAHLINS, Marshall David. Esperando Foucault, ainda. Tradução de Marcela Coelho de Souza e Eduardo Viveiros de Castro. São Paulo: Cosac Naify, 2013.

SAID, Edward W. Orientalismo: o Oriente como invenção do Ocidente. Tradução de Rosana Eichenberg. São Paulo: Companhia das Letras, 2007.

SHIRLEY, Robert Weaver. Antropologia jurídica. São Paulo: Saraiva, 1987.

SIERRA, María Teresa; CHENAUT, Victoria. Los debates recientes y actuales en la antropología jurídica: las corrientes anglosajonas. In: KROTZ, Esteban (Ed.). Antropología jurídica: perspectivas socioculturales en el estudio del derecho. Rubí (Barcelona): Anthropos Editorial; México: Universidad Autónoma Metropolitana - Iztapalapa, 2002. p. 113-170.

TODOROV, Tzvetan. Nous et les autres. La réflexion française sur la diversité humaine. Paris: Éditions du Seuil, 1989.

TREVIÑO, A. Javier. The sociology of law: classical and contemporary perspectives. New Jersey: Transaction Publishers, 2008.

VACHON, Robert. L'Etude du pluralisme juridique: une approche diatopique et dialogale. The Journal of Legal Pluralism and Unofficial Law, London, v. 22, n. 29, p. 163-173, January 1990.

VANDERLINDEN, Jacques. Anthropologie juridique. Paris: Dalloz, 1996.

VILLAS BÔAS FILHO, Orlando. Ancient law: um clássico revisitado 150 anos depois. Revista da Faculdade de Direito da Universidade de São Paulo, São Paulo, v. 106/107, p. 527-562, jan.-dez. 2011/2012.

. A constituição do campo de análise e da pesquisa da antropologia jurídica. Prisma Jurídico, São Paulo, v. 6, p. 333-349, 2007.

. A construção do campo indigenista no Brasil. In: VILLAS BÔAS FILHO, Orlando (Org.). Orlando Villas Bôas e a construção do indigenismo no Brasil. São Paulo: Editora Mackenzie, 2014. p. 153-154. 
VILLAS BÔAS FILHO, Orlando. Os direitos indígenas no Brasil contemporâneo. In: BITTAR, Eduardo Carlos Bianca. História do direito brasileiro: leituras da ordem jurídica nacional. São Paulo: Atlas, 2003. p. 279-293.

. História, direito e a política indigenista brasileira no século XX. In: VILLAS BÔAS FILHO, Orlando (Org.). Orlando Villas Bôas: expedições, reflexões e registros. São Paulo: Metalivros, 2006. p. 32-101.

. Juridicidade: uma crítica à monolatria jurídica como obstáculo epistemológico. Revista da Faculdade de Direito da Universidade de São Paulo, São Paulo, v. 109, p. 281-325, jan.-dez. 2014. 